\title{
Oxidative Phosphorylation, Not Glycolysis, Powers Presynaptic and Postsynaptic Mechanisms Underlying Brain Information Processing
}

\author{
Catherine N. Hall, Miriam C. Klein-Flügge, Clare Howarth, and David Attwell \\ Department of Neuroscience, Physiology and Pharmacology, University College London, London WC1E 6BT, United Kingdom
}

Neural activity has been suggested to initially trigger ATP production by glycolysis, rather than oxidative phosphorylation, for three reasons: glycolytic enzymes are associated with ion pumps; neurons may increase their energy supply by activating glycolysis in astrocytes to generate lactate; and activity increases glucose uptake more than $\mathrm{O}_{2}$ uptake. In rat hippocampal slices, neuronal activity rapidly decreased the levels of extracellular $\mathrm{O}_{2}$ and intracellular $\mathrm{NADH}$ (reduced nicotinamide adenine dinucleotide), even with lactate dehydrogenase blocked to prevent lactate generation, or with only $20 \%$ superfused $\mathrm{O}_{2}$ to mimic physiological $\mathrm{O}_{2}$ levels. Pharmacological analysis revealed an energy budget in which $11 \%$ of $\mathrm{O}_{2}$ use was on presynaptic action potentials, $17 \%$ was on presynaptic $\mathrm{Ca}^{2+}$ entry and transmitter release, $46 \%$ was on postsynaptic glutamate receptors, and $26 \%$ was on postsynaptic action potentials, in approximate accord with theoretical brain energy budgets. Thus, the major mechanisms mediating brain information processing are all initially powered by oxidative phosphorylation, and an astrocyte-neuron lactate shuttle is not needed for this to occur.

\section{Introduction}

Brain function depends critically on an adequate energy supply, in the form of oxygen and glucose provided in the blood, which is largely used on reversing the ion influxes underlying synaptic potentials and action potentials (Attwell and Laughlin, 2001). Averaged over time, brain ATP is almost entirely generated by the complete oxidation of glucose: glycolysis followed by oxidative phosphorylation results in a ratio of oxygen to glucose consumption of $\sim 6: 1$, and oxidative phosphorylation provides $\sim 87 \%$ (26 of 30 molecules) of the ATP generated (Kety, 1957; Sokoloff, 1960). In the short term, however, when neuronal activity increases, ATP has been suggested to be initially produced by glycolysis, for three reasons.

First, both in brain and other tissues, glycolytic membranebound enzymes are directly associated with ion pumps such as the $\mathrm{Na}^{+} / \mathrm{K}^{+}$-ATPase (Knull, 1978; Paul et al., 1979; Mercer and Dunham, 1981; Lipton and Robacker, 1983; Dubinsky et al., 1998), $\mathrm{H}^{+}$-ATPase (Lu et al., 2001), and $\mathrm{Ca}^{2+}$-ATPase (Paul et al., 1989), suggesting that ion transport may be fuelled by ATP produced in a local compartment by glycolysis (Mercer and Dunham, 1981). Second, it has been proposed that neurons regulate their energy supply by turning on glycolysis in astrocytes. When active neurons release glutamate it is taken up into astrocytes,

Received Jan. 3, 2012; revised April 20, 2012; accepted May 9, 2012.

Author contributions: C.N.H., M.C.K.-F., C.H., and D.A. designed research; C.N.H., M.C.K.-F., C.H., and D.A. performed research; C.N.H., M.C.K.-F., C.H., and D.A. analyzed data; C.N.H., M.C.K.-F., C.H., and D.A. wrote the paper.

This work was supported by the European Research Council, Fondation Leducq, and the Wellcome Trust. We thank Paikan Marcaggi and Marieke Schölvinck for early work on this project.

Correspondence should be addressed to David Attwell at the above address. E-mail: d.attwell@ucl.ac.uk.

DOI:10.1523/JNEUROSCI.0026-12.2012

Copyright $@ 2012$ the authors $\quad 0270-6474 / 12 / 328940-12 \$ 15.00 / 0$ which are proposed to use glycolytically derived ATP to power this uptake and the subsequent conversion of glutamate to glutamine, thus producing lactate which is exported to neurons as a substrate for mitochondrial oxidative phosphorylation (Pellerin and Magistretti, 1994; Magistretti et al., 1999). Third, because the increase in oxygen uptake during neural activity was found to be disproportionally small compared to the increase in blood flow and glucose uptake, it was suggested that glycolysis is the main energy-providing mechanism initially supporting neural activity (Fox et al., 1988). The fact that $\mathrm{O}_{2}$ uptake is small relative to the blood flow increase is the basis of BOLD functional imaging (Ogawa et al., 1993).

The notion that neuronal activity initially increases glycolytic ATP production, often assumed to be in astrocytes with subsequent transfer of lactate to neurons for oxidative phosphorylation, has become established in the literature (Hyder et al., 2006; Pellerin et al., 2007; Barros and Deitmer, 2010). However, this concept is based on techniques that have a relatively poor temporal resolution and has been challenged by the demonstration that activity evokes a decrease in extracellular oxygen concentration (Malonek and Grinvald, 1996; Thompson et al., 2003) and a decrease in intracellular NADH (reduced nicotinamide adenine dinucleotide) (Kasischke et al., 2004; Brennan et al., 2006), both of which are consistent with at least some ATP being generated by oxidative phosphorylation.

We demonstrate that oxidative phosphorylation is the main mechanism initially providing energy to power neuronal activity, that the main subcellular mechanisms underlying information processing, i.e., presynaptic action potentials, neurotransmitter release, postsynaptic currents, and postsynaptic action potentials, all consume oxygen, and that an astrocyteneuron lactate shuttle is not needed for oxidative phosphorylation to occur. 


\section{Materials and Methods}

Brain slices. Coronal brain slices (300 $\mu \mathrm{m}$ thick) containing the hippocampus were prepared on a vibratome from postnatal day 21 (P21) Sprague Dawley rats (of either sex), killed by cervical dislocation in accordance with UK government regulations. Slices were incubated for $30 \mathrm{~min}$ at $37^{\circ} \mathrm{C}$, and then for at least $30 \mathrm{~min}$ at room temperature in oxygenated $\left(95 \% \mathrm{O}_{2} / 5 \%\right.$ $\mathrm{CO}_{2}$ ) artificial CSF (ACSF) containing the following (in mM): $124 \mathrm{NaCl}, 2.5$ $\mathrm{KCl}, 26 \mathrm{NaHCO}_{3}, 1 \mathrm{MgCl}_{2}, 1 \mathrm{NaH}_{2} \mathrm{PO}_{4}, 10$ glucose, $2 \mathrm{CaCl}_{2}$, and 1 kynurenic acid (to block glutamate receptors).

Experimental solutions. Slices were perfused with bicarbonate-buffered ACSF, as described above, but without the kynurenic acid, at $35^{\circ} \mathrm{C}$. In experiments using $20 \%$ oxygen, the perfusion solution was bicarbonatebuffered ACSF, gassed with $20 \% \mathrm{O}_{2}, 5 \% \mathrm{CO}_{2}$, and $75 \% \mathrm{~N}_{2}$.

Recording field potentials. Synaptic and action potential activity was evoked by stimulating the Schaffer collaterals in the stratum radiatum of area CA3 with a concentric bipolar tungsten electrode while monitoring the field potential in the stratum pyramidale in CA1, using a glass microelectrode filled with ACSF (see Fig. $1 A$ ). Field potentials were measured with a patch clamp, as the current needed to hold the electrode at $0 \mathrm{mV}$. Consequently, they have a current amplitude given by the voltage deflection occurring in the extracellular space divided by the resistance of the electrode $(\sim 2 \mathrm{M} \Omega)$ and are inverted in sign compared to voltage recordings. Each stimulus was $60 \mu \mathrm{s}$ long, $50-90 \mathrm{~V}$, and delivered at $0.33 \mathrm{~Hz}$ (to monitor the effects of drugs on different components of the field potential) or at $20 \mathrm{~Hz}$ (when evoking sufficient neuronal activity to detect changes in extracellular $\left[\mathrm{O}_{2}\right]$ ). Field potentials were analyzed, as in Figure $1 B$, to provide a measure of the presynaptic action potential volley (proportional to the number of fibers excited), the postsynaptic field potential (fEPSP, proportional to the product of the number of fibers excited and the EPSC evoked in each postsynaptic cell), and the postsynaptic action potential (population spike, determined by the number of postsynaptic cells that fire action potentials in response to the synaptic input).

$\mathrm{O}_{2}$ electrode recordings. Extracellular $\mathrm{O}_{2}$ levels were measured using a glass Clark type oxygen microelectrode with a $10 \mu \mathrm{m}$ tip (Unisense), which was inserted $\sim 100 \mu \mathrm{m}$ into the slice, with its tip center in the stratum radiatum $30 \mu \mathrm{m}$ from the pyramidal cell layer (Fig. $1 A$ ). The electrode was calibrated at least once a week using distilled water at $35^{\circ} \mathrm{C}$ equilibrated with 0,20 , and 100\% oxygen. Oxygen electrode and field potential recordings were acquired using pClamp 10.1 (Molecular Devices), which was also used to control the stimulation. The $\mathrm{O}_{2}$ concentration in the bulk solution entering the bath was $543 \pm 15 \mu \mathrm{M}(n=3)$, i.e., lower than the $\sim 1 \mathrm{~mm}$ in the solution bubbled with $95 \% \mathrm{O}_{2} / 5 \% \mathrm{CO}_{2}$ because of $\mathrm{O}_{2}$ loss through the plastic walls of the tube connecting the solution reservoir to the bath.

NADH imaging. Reduced NADH is fluorescent (Aubin, 1979), while its oxidized form $\mathrm{NAD}^{+}$is not. Reduced NADH in area CA1 of the hippocampus (including the strata radiatum, pyramidale and oriens; see Fig. $1 A$ ) was imaged by focusing just below the slice surface using brightfield microscopy with a $20 \times$ or $40 \times$ water-immersion objective. NADH fluorescence was excited using a xenon arc lamp, with a 300-370 nm excitation filter, $420-490 \mathrm{~nm}$ emission filter, and $410 \mathrm{~nm}$ dichroic filter. Emitted light was imaged using a CoolSnapHQ ${ }^{2} \mathrm{CCD}$ camera and ImagePro software (Media Cybernetics), with an exposure time of $2 \mathrm{~s}$ and a capture rate of $0.41 \mathrm{~Hz}$. Images were analyzed with ImageJ software.

Experimental protocol. For most experiments NADH images, field potential recordings, and $\left[\mathrm{O}_{2}\right]$ measurements were obtained simultaneously. The standard protocol (Fig. $2 \mathrm{~A}$ ) consisted of two phases: $30 \mathrm{~s}$ of $0.33 \mathrm{~Hz}$ stimulation followed (after $30 \mathrm{~s}$ with no stimulation) by $10 \mathrm{~s}$ of stimulation at $20 \mathrm{~Hz}$ to generate an easily detectable metabolic response in the tissue (no stimulation was applied after this). The frequency of 20 $\mathrm{Hz}$ is similar to the peak firing rate produced in CA3 cells in vivo for optimal stimuli (mean value of $13 \mathrm{~Hz}$, but extending up to $25 \mathrm{~Hz}$ ) (Leutgeb et al., 2007).

This protocol was then repeated three times at an interval of 6 min for each drug condition, and the field potential, $\mathrm{O}_{2}$, and $\mathrm{NADH}$ results from each triplicate were averaged. The first triplicate in each slice was drug free and was used as a control to which later triplicates were normalized. Since responses might change with time even under control conditions, to assess the effect of drugs we first assessed whether the response to a second control triplicate differed significantly from the first triplicate, and, if it did, we compared the mean response in the second triplicate performed in the presence of drug with the mean response in the second triplicate performed in the absence of drug. For most experiments (including all from which the field potential was analyzed), $1 \mu \mathrm{M}$ TTX was added for the final stimulation triplicate. TTX abolishes all components of the field potential leaving only the stimulation artifact (Fig. $1 B$ ), which was subtracted from the previous recordings from the same slice to reveal the various field potential components.

Lactate measurements. To assess the effect of the lactate dehydrogenase (LDH) inhibitor oxamate on hippocampal slice lactate levels, slices were incubated in $1 \mathrm{ml} \mathrm{ACSF}$ with and without $20 \mathrm{~mm}$ oxamate at $37^{\circ} \mathrm{C}$ for 5 min (the earliest time at which measurements were taken after incubating slices with oxamate in the stimulation experiments). The slices were then removed, and the bathing solution was assayed for lactate content using a commercially available colorimetric assay based on the reaction of lactate oxidase (Abcam; some other lactate sensors are based on lactate dehydrogenase which would be inappropriate for experiments attempting to block this enzyme in the cells). This gave an absorbance proportional to lactate concentration over the range 0 to $10 \mathrm{~mm}$, and the lactate concentration in the bathing ACSF was determined by comparison to known lactate concentrations. Oxamate $(20 \mathrm{~mm})$ did not affect the slope or intercept of the graph of absorbance as a function of concentration (slope increased by $3.6 \%, p=0.87$; intercept increased by $1 \%, p=0.93$ ), implying that oxamate did not inhibit the assay lactate oxidase.

Statistics. Statistical analysis was conducted using SPSS 16 or the StatTools resources (http://department.obg.cuhk.edu.hk/researchsupport/statmenu. asp). Unless stated otherwise, Student's two-tailed $t$ test was used. Where multiple comparisons are presented, $p$ values were corrected using a procedure equivalent to the Holm-Bonferroni method (for $N$ comparisons, the most significant $p$ value is multiplied by $N$, the second most significant by $N-1$, the third most significant by $N-2$, etc.; corrected $p$ values are significant if they are $<0.05)$. Data are presented as mean \pm SEM.

\section{Results}

\section{Experimental approach}

In this paper we use hippocampal slices to assess how energy is provided in response to stimulated activity by combining oxygen electrode recording, NADH imaging, and modeling of how $\mathrm{O}_{2}$ concentration changes relate to $\mathrm{O}_{2}$ consumption. The slice preparation is crucial for these experiments for three reasons. First, unlike for cultured cells, the spatial relationship of neurons and astrocytes is preserved. Second, it allows pharmacological agents to be applied at a defined concentration. Third, and most importantly, unlike in intact brain, oxygen is supplied to the slice by diffusion from the perfusing solution, so that changes in the oxygen concentration in the slice reflect only changes in the rate of oxygen use and do not require complex modeling to interpret (Gjedde, 2005). This is critically different from the in vivo brain, where the amount of oxygen supplied by the blood is often altered by the same experimental manipulations that alter oxygen use, confounding the interpretation of experiments. For example, glutamate receptor antagonists and inhibition of lactate production, as used below, will decrease blood flow (Brazitikos et al., 1993; Akgören et al., 1994; Li and Iadecola, 1994; Gordon et al., 2008), reducing oxygen supply (Offenhauser et al., 2005) and confounding the quantification of any effect on oxygen consumption.

\section{Neuronal activity lowers extracellular $\mathrm{O}_{2}$ and intracellular NADH levels}

Figure 1, $A$ and $B$, shows the experimental arrangement and typical field potentials recorded when stimulating the Schaffer collaterals at $0.33 \mathrm{~Hz}$, including a small and brief presynaptic action potential volley, the field EPSP (a downward deflection when 
measured as a current, lasting about 15 $\mathrm{ms}$ ), and the population spike (a brief upward deflection reflecting the occurrence of postsynaptic action potentials).

On advancing the oxygen electrode from the bulk perfusion solution to a position $\sim 100 \mu \mathrm{m}$ below the surface of the slice, the $\mathrm{O}_{2}$ level decreased from the bulk solution value of $543 \mu \mathrm{M}$ (see Materials and Methods) to a mean value of $212 \pm 17 \mu \mathrm{M}$ in 86 slices. A $10 \mathrm{~s}$ train of stimulation at $20 \mathrm{~Hz}$ produced a decrease of $\mathrm{O}_{2}$ level of $118 \pm 8$ $\mu \mathrm{M}$ in 86 slices (Fig. $1 C$, specimen trace). At the same time there was a $1.4 \pm 0.2 \%$ initial decrease in $\mathrm{NADH}$ fluorescence (averaged over the CA1 region), followed by a $2.4 \pm$ $0.3 \%$ increase above the original level (in 26 slices; Fig. $1 D$, specimen trace). In the stratum oriens, the resting NADH fluorescence was a little lower than in the strata pyramidale or radiatum (Fig. 1E), but neither the initial decrease of $\mathrm{NADH}$ level evoked by stimulation (Fig. $1 F$ ) nor the overshoot of [NADH] after stimulation (Fig. $1 G$ ) differed significantly between the three layers.

The decrease of $\left[\mathrm{O}_{2}\right]$ implies that the rate of ATP production by oxidative phosphorylation has been increased. This may be due to ATP consumption leading to a rise in the [ADP $] /[\mathrm{ATP}]$ ratio (Chance and Williams, 1955), due to a rise of mitochondrial $\left[\mathrm{Ca}^{2+}\right]$ activating the $\mathrm{F}_{0} \mathrm{~F}_{1}$-ATPase (Territo et al., 2000) (but see Gellerich et al., 2010), or due to a rise of extramitochondrial $\left[\mathrm{Ca}^{2+}\right]_{\mathrm{i}}$ activating the mitochondrial aspartate-glutamate exchanger aralar (Contreras and Satrústegui, 2009; Gellerich et al., 2009), which raises $[\mathrm{NADH}]$ in mitochondria and thus supports $\mathrm{H}^{+}$pumping out across the mitochondrial membrane. We will show below that the majority of the ATP produced in response to neuronal activity is by oxidative phosphorylation. The fall of NADH level is expected if neuronal activity increases oxidative phosphorylation to a rate that consumes NADH faster than it can be provided by the tricarboxylic acid (TCA) cycle and glycolysis (Fig. $1 H$ ). The subsequent overshoot in $[\mathrm{NADH}]$ to a value higher than the original level may reflect a late activation of glycolysis in astrocytes or neurons (Kasischke et al., 2004) as is sometimes assumed, but could alternatively be due to increased NADH production by the TCA cycle (Brennan et al., 2006) occurring when a rise of mitochondrial $\left[\mathrm{Ca}^{2+}\right]_{\mathrm{i}}$ activates mitochondrial dehydrogenases (Duchen, 1992) (for review, see Gunter et al., 2004; Gellerich et al., 2010) (but see Mathiesen et al., 2011).

\section{$\mathrm{O}_{2}$ use on different subcellular mechanisms}

The main energy-demanding processes mediating information processing, i.e., presynaptic action potentials, transmitter release, postsynaptic currents, and postsynaptic action potentials (At-
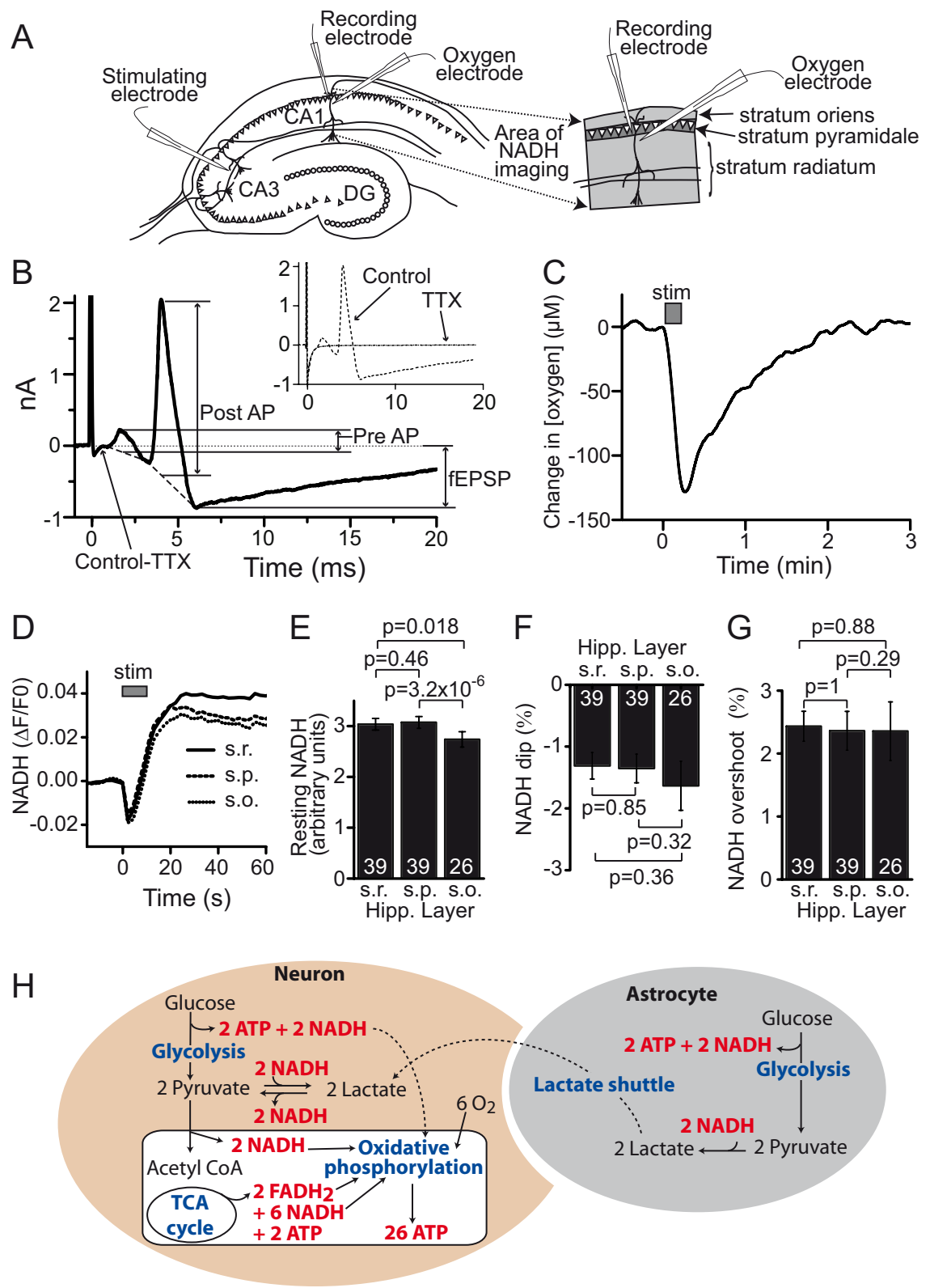

Figure 1. Stimulus-evoked field potentials and $\mathrm{O}_{2}$ and NADH changes. $\boldsymbol{A}$, Diagram of the electrode positions and area imaged. $\boldsymbol{B}$, Inset: Specimen field potentials evoked at $0.33 \mathrm{~Hz}$, in the absence and presence of TTX. Main panel: Trace from inset without TTX minus the trace in $T T X$, annotated to show how field potential amplitudes were measured. $C$, Decrease of extracellular $\left[\mathrm{O}_{2}\right]$ evoked by $10 \mathrm{~s} \mathrm{of} 20 \mathrm{~Hz}$ stimulation. $D$, Biphasic NADH response (change in fluorescence/fluorescence at the start of stimulation, $\Delta F / F 0$ ) evoked by $10 \mathrm{~s}$ of $20 \mathrm{~Hz}$ stimulation in the stratum radiatum (s.r.), stratum pyramidale (s.p.), and stratum oriens (s.o.). $\boldsymbol{E}-\boldsymbol{G}$, Resting NADH fluorescence (E), decrease of NADH fluorescence evoked by $20 \mathrm{~Hz}$ stimulation $(\boldsymbol{F})$, and subsequent increase of NADH fluorescence above resting level $(\boldsymbol{G})$ in the s.r., s.p., and s.o. All $p$ values are from paired $t$ tests. $\boldsymbol{H}$, How the rates of glycolysis, the TCA cycle, and oxidative phosphorylation determine whether the NADH level falls or rises. An increase in the rate of oxidative phosphorylation will lower [NADH]. An increase in the rate of glycolysis (in astrocytes or in neurons) will increase [NADH], if not balanced by NADH consumption in the conversion of pyruvate to lactate, as will an increase in the rate of the tricarboxylic acid cycle. Lactate dehydrogenase is proposed to convert pyruvate to lactate in astrocytes, and lactate to pyruvate in neurons.

twell and Laughlin, 2001), occur in different subcellular compartments, and thus may differ in their dependence on ATP generation by glycolysis and oxidative phosphorylation. To assess this, we applied drugs to block, successively, postsynaptic currents and postsynaptic action potentials [10 $\mu \mathrm{M}$ NBQX and $50 \mu \mathrm{M}$ D-AP5 (NBQX+AP5)], presynaptic transmitter release and downstream postsynaptic events $\left(250 \mu \mathrm{M} \mathrm{Cd}^{2+}\right)$, and finally all action potentials and synaptic events $(1 \mu \mathrm{M}$ TTX). 
A
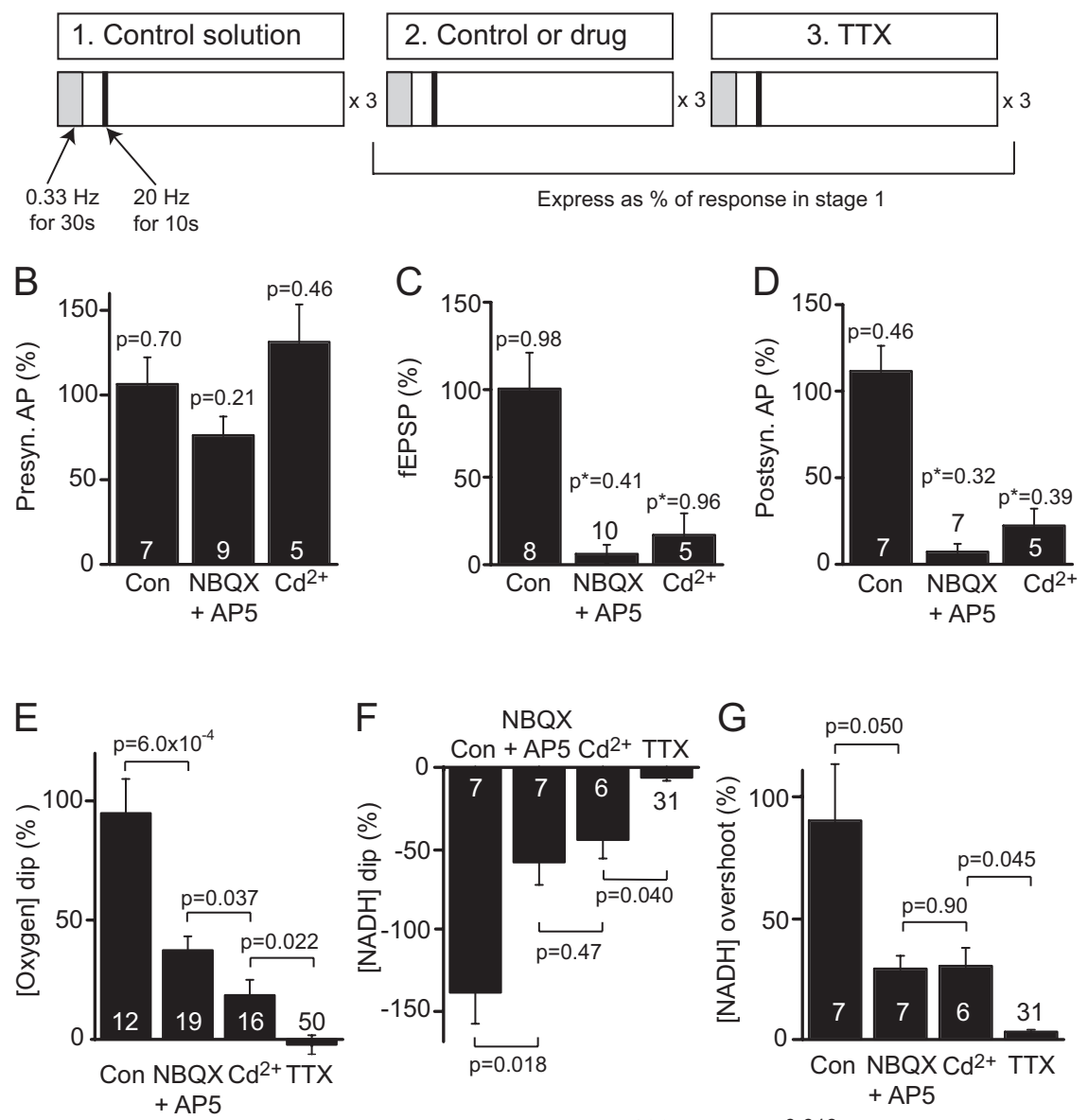

$\mathrm{H}$
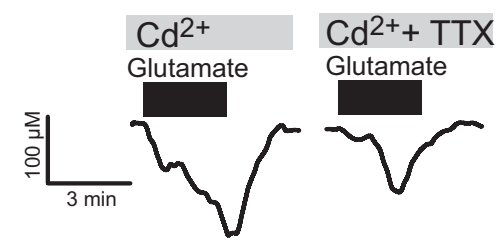

3. TTX

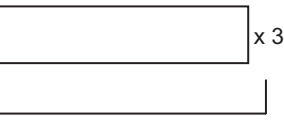

onse in stage 1

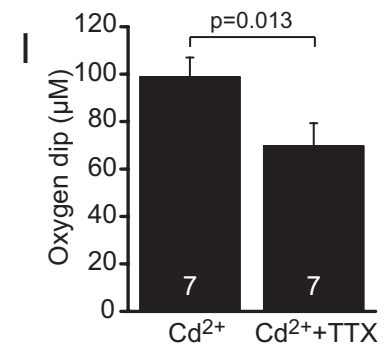

Figure 2. Pharmacological analysis of $\mathrm{O}_{2}$ use on different subcellular mechanisms. $A$, Schematic showing experimental protocol, with three stimulation sets in each condition applied at 6 min intervals (see Materials and Methods): during the first stimulation phase, no drug is present for all slices. In the second phase, some slices are exposed to drug, while some remain drug free as controls. In the third phase, 1 $\mu \mathrm{m}$ TTX is applied (to allow subtraction of the stimulation artifact from the field potential data). Responses in phase 2 are reported as a percentage of the response in phase 1 , to normalize to the number of axons activated in each slice. Comparing the normalized responses for control and drug in phase 2 defines the effect of the drug tested. $\boldsymbol{B}-\boldsymbol{D}$, Amplitude of presynaptic action potential volley $(\boldsymbol{B})$, postsynaptic field EPSP $\left(\boldsymbol{C}\right.$, and postsynaptic action potential population spike $(\boldsymbol{D})$ measured as in Figure $1 B$, in the presence of NBQX $+A P 5$ or $C^{2+}$ together with the amplitude seen on the second application of $20 \mathrm{~Hz}$ stimulation in the absence of drugs (Con). The $p$ values are from one sample $t$ tests comparing with $100 \%$ (the response in the first stimulation phase), unless marked with an asterisk, in which case the comparison is versus zero. $\boldsymbol{E}-\boldsymbol{G}$, Amplitude of the $\left[0_{2}\right]$ decrease $(\boldsymbol{E})$, decrease in NADH fluorescence $(\boldsymbol{F})$, and overshoot of NADH fluorescence above its baseline value $(\boldsymbol{G})$ in the presence of $\mathrm{NBQX}+\mathrm{AP5}, \mathrm{Cd}^{2+}$, and $\mathrm{TTX}$, compared to the amplitude seen on the second application of $20 \mathrm{~Hz}$ stimulation in the absence of drugs (Con; these values are not significantly different from the responses to the first set of stimuli). Incrementally blocking postsynaptic activity (NBQX+AP5), transmitter release $\left(\mathrm{Cd}^{2+}\right)$, and all evoked activity (TTX) incrementally decreased the $\left[\mathrm{O}_{2}\right]$ decrease. The $p$ values are from unpaired $t$ tests, corrected for multiple comparisons. $\boldsymbol{H}, \boldsymbol{I}$, Specimen traces $(\boldsymbol{H})$ and mean values $(I)$ for the decrease of $\left[0_{2}\right]$ evoked by $500 \mu \mathrm{m}$ glutamate in $250 \mu \mathrm{m} \mathrm{Cd}^{2+}$ and in $\mathrm{Cd}^{2+}+1 \mu \mathrm{m} T \mathrm{TX}$. The resting $\left[0_{2}\right]$ was not significantly affected by $\mathrm{Cd}^{2+}$ (reduced by $42 \pm 36 \% ; p=0.29$ ) nor by $\Pi \mathrm{TX}$ (in $\mathrm{Cd}^{2+}$; reduced by $12 \pm 36 \% ; p=0.75$ ) in seven slices.

To assess the effects of the drugs used, we analyzed the extracellular field potentials. As expected, postsynaptic currents and postsynaptic action potentials were selectively abolished by $\mathrm{NBQX}+\mathrm{AP} 5$, with no significant effect on the presynaptic action potential (Fig. $2 A-D$ ). $\mathrm{Cd}^{2+}$ also abolished postsynaptic events but spared the presynaptic action potential, while TTX abolished all electrical activity (Fig. $1 B$ ). We also tried using muscimol $(20 \mu \mathrm{M})$ to activate $\mathrm{GABA}_{\mathrm{A}}$ receptors and thus prevent the postsynaptic cells from firing action potentials (Caesar et al., 2003), in an attempt to define the $\mathrm{O}_{2}$ use on postsynaptic action potentials. However, as observed by Jang et al. (2005), high levels of muscimol reduced the field EPSP by $\sim 40 \%$ (data not shown), suggesting that presynaptic $\mathrm{GABA}_{\mathrm{A}}$ receptors reduce transmitter release, which would have confounded our allocation of $\mathrm{O}_{2}$ consumption to different subcellular mechanisms.

Blocking postsynaptic currents, and the postsynaptic action potentials they produce, with $\mathrm{NBQX}+\mathrm{AP} 5$ reduced the $20 \mathrm{~Hz}$ stimulation evoked decrease of $\mathrm{O}_{2}$ level by $63 \%\left(p=2.7 \times 10^{-9}\right.$, compared to the preceding responses in the absence of drugs). The response in $\mathrm{NBQX}+\mathrm{AP} 5$ was significantly smaller than the $\mathrm{O}_{2}$ response to a second set of stimulation in the absence of any drug $\left(p=6 \times 10^{-4}\right.$, Fig. $\left.2 E\right)$, while applying the stimulation twice with no drug application had no significant effect on the $\mathrm{O}_{2}$ decrease ( $p=0.73$; Fig. $2 E$, Con). Applying $\mathrm{Cd}^{2+}$, to additionally block presynaptic processes controlling transmitter release downstream of $\mathrm{Ca}^{2+}$ entry as well as all processes (in addition to postsynaptic currents) activated by transmitter release [such as uptake and metabolic processing of transmitter, and activation of metabotropic glutamate receptors (mGluRs)], reduced the $\mathrm{O}_{2}$ decrease by an additional 19\% (Fig. 2E), while TTX abolished the $\mathrm{O}_{2}$ decrease. A similar series of reductions of the NADH fluorescence decrease (Fig. $2 F$ ), and overshoot (Fig. 2G) was seen when these drugs were applied. The NADH changes seen on drug application were not significantly different across the layers of the hippocampus (repeated-measures ANOVA, $p=0.42$ ), so for this and subsequent experiments $\mathrm{NADH}$ data were averaged across the whole CA1 region.

These data indicate that oxidative phosphorylation is used to generate at least some of the ATP used to power presynaptic action potentials, presynaptic processes controlling transmitter release, and postsynaptic currents and action potentials.

Separating postsynaptic $\mathrm{O}_{2}$ use on glutamate-gated currents and action potentials

Calculations presented below show that the $63 \%$ reduction of the $\left[\mathrm{O}_{2}\right]$ decrease produced by NBQX $+\mathrm{AP} 5$ implies that $72 \%$ of the 
$\mathrm{O}_{2}$ is used postsynaptically. However, this does not distinguish $\mathrm{O}_{2}$ use on postsynaptic glutamate receptor currents and on postsynaptic action potentials. To determine whether both or just one of these processes is powered by ATP from oxidative phosphorylation, we applied glutamate $(500 \mu \mathrm{M})$ to activate AMPA/KA, NMDA, and metabotropic glutamate receptors, and thus to generate action potentials (the glutamate level reached deep in the slice will be in the low micromolar range because of uptake) (Amato et al., 1994). The experiments were performed in the presence of $250 \mu \mathrm{M} \mathrm{Cd}^{2+}$ to prevent the evoked action potentials from releasing more neurotransmitter. Repeated application of glutamate $\left(\right.$ in $\mathrm{Cd}^{2+}$ ) evoked an $\left[\mathrm{O}_{2}\right]$ decrease that was not significantly different on the second application ( $p=0.93$; Fig. $2 I$, $\mathrm{Cd}^{2+}$ ), while if TTX was present during the second glutamate application (to block glutamate-evoked action potentials but not $\mathrm{Na}^{+}$entry through glutamate-gated channels), the $\mathrm{O}_{2}$ decrease was reduced by $29 \%(p=0.013 ; n=7$; Fig. $2 H, I)$, reflecting the suppression of $\mathrm{O}_{2}$ use on reversing the ion movements associated with action potentials.

The dependence of action potential firing rate on mean glutamate-gated current, and hence the relative magnitudes of the ion influxes through glutamate-gated channels and through voltage-gated $\mathrm{Na}^{+}$channels, may differ when action potentials are evoked by superfusing glutamate (as here) and by activating the Schaffer collateral input (as in Fig. 2 E). In addition, superfusion of glutamate may activate extrasynaptic and astrocyte receptors that are not activated by synaptic glutamate release. However, the data in Figure 2, $H$ and $I$, demonstrate that activation of glutamate receptors, and the action potentials this produces, both evoke $\mathrm{O}_{2}$ use on ATP production by oxidative phosphorylation.

\section{Oxidative phosphorylation is evoked by neuronal activity at physiological $\mathrm{O}_{2}$ levels}

The experiments described above used, as is customary, 95\% oxygen $(\sim 1 \mathrm{mM})$ in the superfusion solution, which leads to an oxygen level in the brain slices of $\sim 150-400 \mu \mathrm{M}$ (at different depths in the slice) (see Fig. $6 A, B$ ), which is much higher than the in vivo value of 20-60 $\mu \mathrm{M}$ (Dings et al., 1998; Offenhauser et al., 2005). The fraction of ATP which is produced by oxidative phosphorylation might be reduced by the lower in vivo value, which can be mimicked by superfusing brain slices with solution equilibrated with 20\% oxygen (Hall and Attwell, 2008), giving an oxygen level of 2-130 $\mu \mathrm{M}$ at different depths in the slice (data not shown). We therefore investigated the changes of $\mathrm{O}_{2}$ level and $\mathrm{NADH}$ fluorescence produced by neuronal activity in slices superfused with solution containing $20 \% \mathrm{O}_{2}$.

Switching from $95 \%$ to $20 \% \mathrm{O}_{2}$ in the superfusion solution did not significantly affect the amplitude of the presynaptic action potential $(p=0.24)$, though the postsynaptic fEPSP $(38 \%$ decrease; $\left.p=1.3 \times 10^{-4}\right)$ and the postsynaptic population spike (15\% decrease; $p=0.014$; Fig. $3 A$ ) were significantly reduced. This reduction in postsynaptic responses may reflect a rise in the adenosine concentration in the slice in the lower $\mathrm{O}_{2}$ solution (Gordon et al., 2008), which acts on presynaptic receptors to reduce glutamate release. As was shown in Figure $2 B-D$ for $95 \%$ $\mathrm{O}_{2}$, NBQX+AP5 abolished the fEPSP and population spike, with no effect on the presynaptic action potential, while TTX abolished all evoked electrical activity ( $n=5-6$ slices) (data not shown).

In $20 \% \mathrm{O}_{2}$, the resting $\mathrm{O}_{2}$ level before stimulation was $115 \pm$ $25 \mu \mathrm{M}(n=18)$, i.e., only $54 \%$ of the value measured with $95 \% \mathrm{O}_{2}$ in the superfusion solution. Thus, there is less $\mathrm{O}_{2}$ available to be
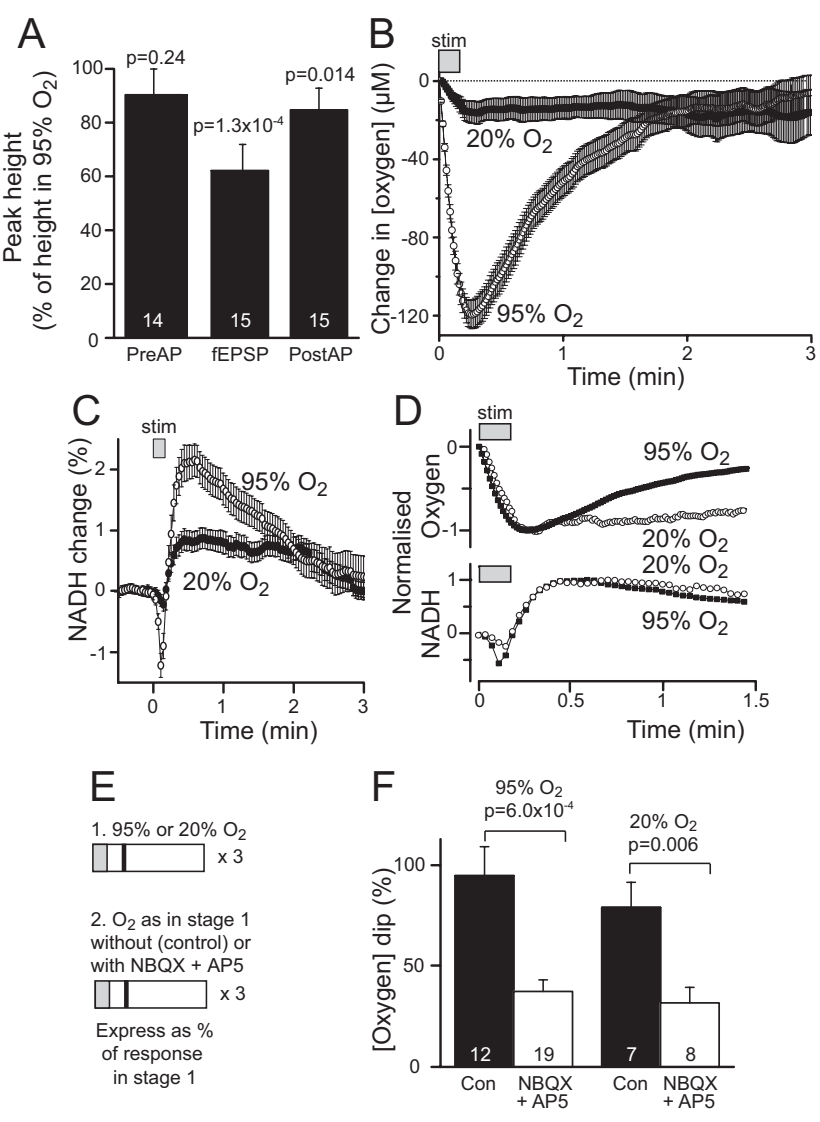

Figure 3. Oxidative phosphorylation powers neuronal activity at physiological $\left[\mathrm{O}_{2}\right] . A$, Effect of switching from $95 \%$ to $20 \% \mathrm{O}_{2}$ in the superfusion solution on the amplitude of the presynaptic action potential, the postsynaptic fEPSP, and the postsynaptic action potential (population spike). $\boldsymbol{B}$, Mean time course of $\left[\mathrm{O}_{2}\right]$ decrease in $20 \% \mathrm{O}_{2}$ solution in 15 slices, compared with that in $95 \% \mathrm{O}_{2}$ solution ( 56 slices). C, Mean time course of NADH changes in $20 \%$ and $95 \% 0_{2}$ solution (in 11 and 15 slices, respectively). D, Oxygen and NADH responses in 20\% (open circles) and $95 \%$ (filled squares) ${ }_{2}$, normalized to the peak dip and overshoot, respectively. $\boldsymbol{E}, \boldsymbol{F}$, Effect of GluR blockers on $\mathrm{O}_{2}$ dip in $95 \%$ and $20 \% \mathrm{O}_{2}$. E, Experimental design. The first stimuli were presented in $95 \%$ or $20 \% \mathrm{O}_{2}$. The same $\left[\mathrm{O}_{2}\right]$ was maintained for the second stage, when NBQX + AP5 was applied to 8 of 15 slices in $20 \% \mathrm{O}_{2}$ or 19 of 31 slices in $95 \% \mathrm{O}_{2}$. F, Effect of $\mathrm{NBQX}+\mathrm{AP} 5$ on the oxygen dip in $95 \%$ and $20 \% \mathrm{O}_{2}$. Control bars show response to second stimulation normalized to response to first stimulation in the same $\mathrm{O}_{2}$ (not significantly different from the response to the first stimulation, $p=0.73$ for $95 \% ; 0.14$ for $20 \% 0_{2}$ ). NBQX + AP5 bars show response to second stimulation in NBQX + AP5 normalized to response to first stimulation without drugs in the same $\mathrm{O}_{2}$. There was no significant difference between the effect of $\mathrm{NBQX}+\mathrm{AP5}$ in the two $\mathrm{O}_{2}$ concentrations (univariate ANOVA, $p=0.64$ ).

consumed during periods of increased energy demand, and stimulation of the Schaffer collaterals could not lower the $\left[\mathrm{O}_{2}\right]$ by the same amount as occurs in $95 \% \mathrm{O}_{2}$ solution $(\sim 120 \mu \mathrm{M}$; Fig. 1$)$. Accordingly, the initial decrease in $\left[\mathrm{O}_{2}\right]$ was only $22 \pm 3 \%$ of that seen in $95 \% \mathrm{O}_{2}$ solution, but the time course of the dip was significantly prolonged (Fig. $3 B, D$; it recovered to baseline in $\sim 5 \mathrm{~min}$ ), consistent with ion pumping being powered by oxidative phosphorylation for a longer period after neuronal activity in $20 \% \mathrm{O}_{2}$. Similarly, the initial decrease and late overshoot of $\mathrm{NADH}$ fluorescence averaged over the CA1 area were also reduced in $20 \% \mathrm{O}_{2}$ solution (Fig. 3C). Switching from $95 \%$ to $20 \% \mathrm{O}_{2}$ solution increased the resting $\mathrm{NADH}$ fluorescence by $5 \pm 2 \%(p=0.018 ; n=15)$. The time courses of the $\left[\mathrm{O}_{2}\right]$ and $[\mathrm{NADH}]$ changes are compared in Figure $3 D$. At both superfused $\mathrm{O}_{2}$ levels, the overshoot of the NADH concentration overlaps with much of the period of increased $\mathrm{O}_{2}$ use. 

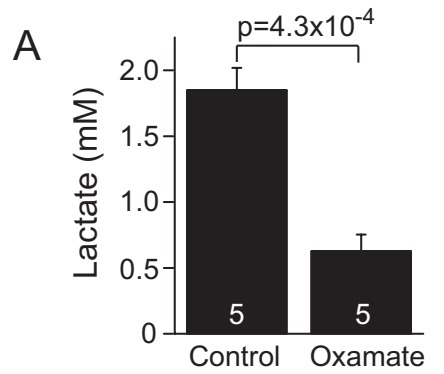

B

\section{Control 2. Control or oxamate}
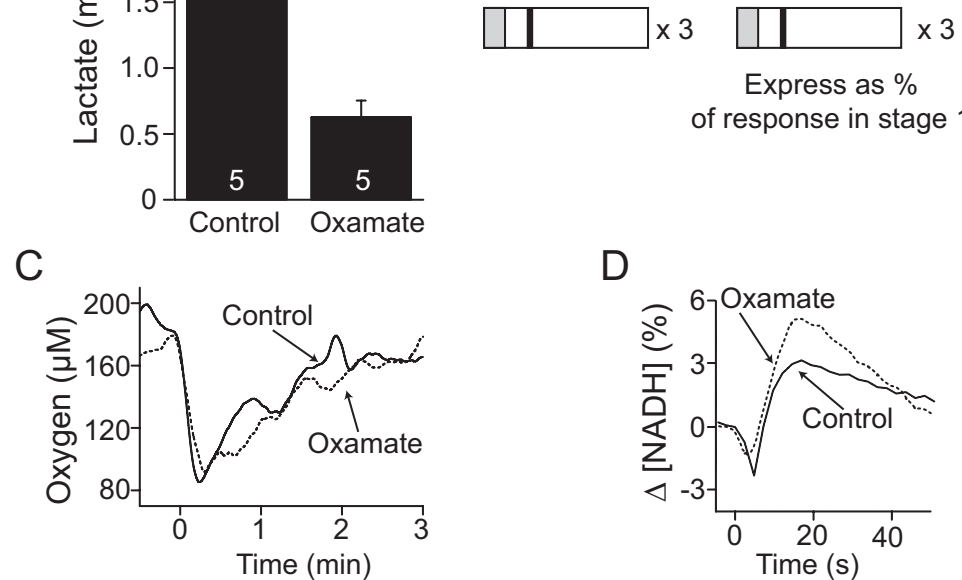

D
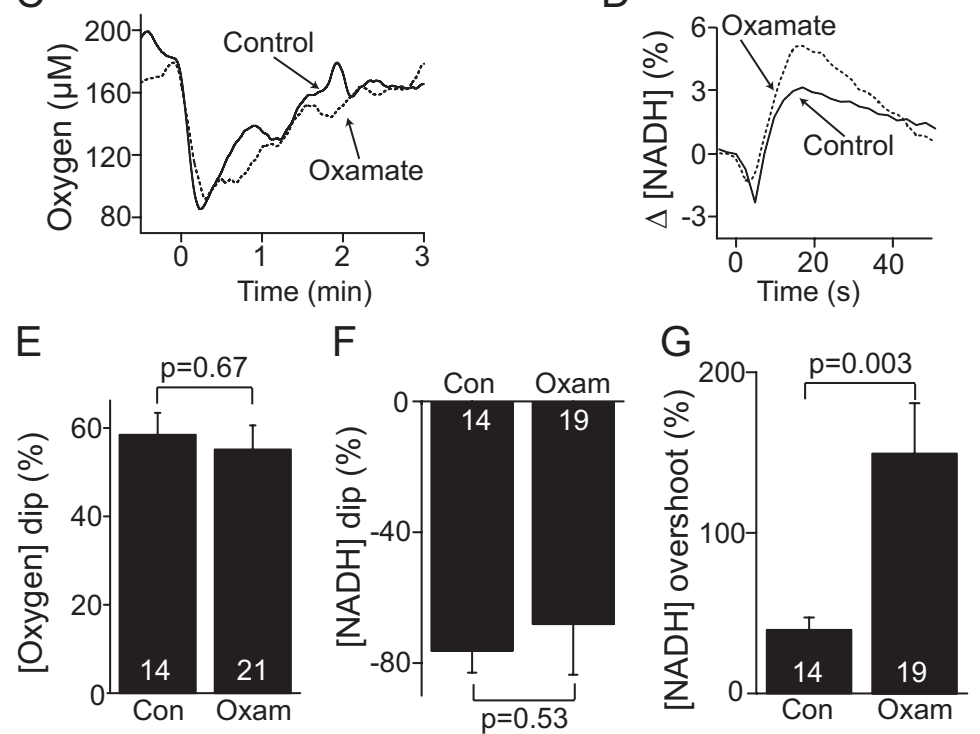

Figure 4. Blocking $\mathrm{LDH}$ does not affect the $\left[\mathrm{O}_{2}\right]$ and $[\mathrm{NADH}]$ decreases. $\boldsymbol{A}$, Effect of $\mathrm{LDH}$ inhibition on lactate level in the extracellular solution ( 5 slices). Oxamate significantly inhibits lactate accumulation (the inhibition of LDH is even stronger than the reduction in lactate concentration shown in the graph, because lactate made before the oxamate was applied will not be removed by the oxamate). $\boldsymbol{B}$, Experimental protocol. Oxamate was added or not added during stage 2 , and responses in $\boldsymbol{E}-\boldsymbol{G}$ were expressed as a percentage of those in stage $1 . C, D$, Example traces showing the effect of $20 \mathrm{~mm}$ oxamate on the $\mathrm{O}_{2}$ transient $(\boldsymbol{C})$ and the NADH dip and overshoot produced by Schaffer collateral stimulation (D). $E-G$, Mean data showing the effect of oxamate on the $\left[\mathrm{O}_{2}\right]$ decrease $(\boldsymbol{E})$, initial NADH fluorescence decrease $(\boldsymbol{F})$, and late NADH fluorescence increase $(\boldsymbol{G})$, normalized as in $\boldsymbol{B}$. Solutions contained $95 \% \mathrm{O}_{2}$.

In the presence of NBQX+AP5, to block postsynaptic currents and action potentials, the $\mathrm{O}_{2}$ decrease was reduced to $32 \%$ of the value obtained in the absence of drugs, not significantly different to the reduction to $37 \%$ produced by NBQX $+\mathrm{AP} 5$ in $95 \% \mathrm{O}_{2}$ solution (Fig. 3E, F, statistics are given in the legend). Thus, the fraction of $\mathrm{O}_{2}$ consumption that is on postsynaptic activity is approximately independent of $\mathrm{O}_{2}$ level.

\section{Effect of blocking lactate dehydrogenase}

The astrocyte-neuron lactate shuttle hypothesis proposes that astrocytes carry out glycolysis and use LDH to convert the end product of glycolysis, pyruvate, into lactate, which is transferred to neurons where neuronal LDH converts it back to pyruvate to fuel neuronal oxidative phosphorylation (Fig. $1 H$ ). To test this hypothesis, we blocked LDH in astrocytes and neurons using $20 \mathrm{~mm}$ oxamate (the $\mathrm{IC}_{50}$ for block is $0.6-4.4 \mathrm{~mm}$ ) (Wu et al., 2007). After $5 \mathrm{~min}$, oxamate significantly reduced lactate levels in the bathing ACSF by $66 \pm 7 \%$ $\left(p=4.3 \times 10^{-4}\right)$ (Fig. $\left.4 A\right)$, consistent with LDH being inhibited. According to the astrocyte-neuron lactate shuttle idea, this ought to reduce or abolish the $\mathrm{O}_{2}$ decrease evoked by neuronal activity.

Blocking LDH also allows us to put limits on the relative importance of ATP production by oxidative phosphorylation and glycolysis. With interconversion of pyruvate and lactate blocked, if glycolytic ATP production were dominant, neuronal activity would produce a rise of NADH level, not a fall. Inspection of Figure $1 \mathrm{H}$ shows that, with $\mathrm{LDH}$ blocked, glycolysis generates $1 \mathrm{NADH}$ molecule per ATP produced, and glycolysis followed by pyruvate entering the TCA cycle generates 2.5 NADH molecules per ATP produced, while oxidative phosphorylation consumes $10 / 26$ or 0.38 NADH molecules per ATP produced. It follows that a rise of $[\mathrm{NADH}]$ is expected if, averaged over all the astrocytes and neurons imaged, the rate of production of ATP by glycolysis is $>38 \%$ of the rate of ATP production by oxidative phosphorylation (or if the rate of ATP production by glycolysis followed by the TCA cycle is $>38 \% / 2.5=15 \%$ of that produced by oxidative phosphorylation). Thus, if neuronal activity evokes a fall of NADH fluorescence, it implies that oxidative phosphorylation generates $>100 \%-38 \%=62 \%$ of the ATP powering the increase of neuronal activity (assuming that $\mathrm{NADH}$ generated in the cytoplasm rapidly equilibrates with mitochondrial $\mathrm{NADH}$, the fluorescence of which may be enhanced by binding to proteins such as complex 1) (Blinova et al., 2008).

In the presence of oxamate, the resting level of $\left[\mathrm{O}_{2}\right]$ and $\mathrm{NADH}$ fluorescence were unchanged (reduced by $1 \pm 6 \%, p=$ $0.83, N=11$ and by $2 \pm 2 \%, p=0.32$, $N=13$, respectively). Furthermore, although oxamate reduced and slowed the field EPSC and population spike (see below, Effects of oxamate on field potentials), neuronal activity still evoked a decrease of $\left[\mathrm{O}_{2}\right]$ and of NADH fluorescence (Fig. 4C,D), and the amplitudes of these decreases were not significantly different from when oxamate was absent $(p=0.67$ and 0.53 respectively; Fig. $4 E, F)$. However, oxamate significantly increased the late overshoot of NADH fluorescence ( $p=0.003$; Fig. $4 G$ ). This is expected because, when glycolysis is activated with a delay after stimulation (Kasischke et al., 2004) and produces pyruvate, block of the conversion of pyruvate to lactate results in less consumption of $\mathrm{NADH}$ (see Fig. $1 \mathrm{H}$ ) and allows more pyruvate to enter the NADH-generating TCA cycle (which is being activated; Brennan et al., 2006).

Although oxamate is widely used as an inhibitor of $\mathrm{LDH}$, it also inhibits pyruvate decarboxylase (an enzyme expressed in astrocytes and neurons, which converts pyruvate to oxaloacetate to top up the TCA cycle with molecules) and, when pyruvate levels are low, pyruvate uptake into mitochondria (MartinRequero et al., 1986a,b). Furthermore it can produce a small inhibition of aspartate aminotransferase (Rej, 1979), a component of the malate-aspartate shuttle that transfers cytoplasmic NADH into mitochondria. These effects are unlikely to be significant in our preparation, since inhibition of pyruvate uptake, the TCA cycle, or NADH uptake in mitochondria would decrease 

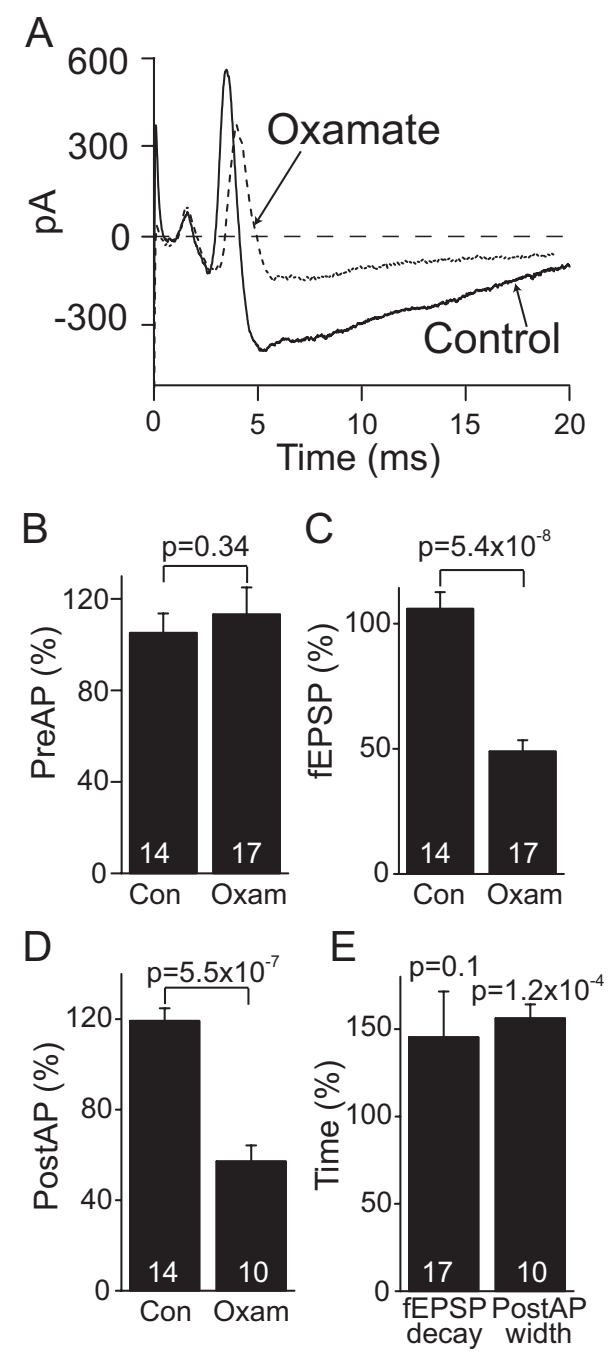

Figure 5. Effects of oxamate on field potentials. $A$, Example traces showing the effect of 20 mm oxamate on the field potential produced by Schaffer collateral stimulation. $\boldsymbol{B}-\boldsymbol{D}$, Effect of oxamate on the presynaptic action potential volley (preAP; $\boldsymbol{B})$, the fEPSP $(\boldsymbol{C})$, and the postsynaptic population spike (postAP; $\boldsymbol{D})$. $\boldsymbol{E}$, Effect of oxamate on the half-maximum width of the population spike and on the fEPSP decay time constant. In control conditions, repeated stimulation had no effect on the kinetics of the population spike (half-maximum width, $110 \pm 3 \%$ of that for first stimuli; $p=0.12 ; n=10$ ) or fEPSP (decay time constant, $114 \pm 20 \% ; p=0.47$; $n=9)$.

oxidative phosphorylation, yet in our experiments the activityevoked $\left[\mathrm{O}_{2}\right]$ decrease was unaffected by oxamate.

The fact that neuronal activity still evokes a fall of both $\left[\mathrm{O}_{2}\right]$ and $[\mathrm{NADH}]$ with LDH blocked implies that the majority of the ATP (at least 62\%, see above) that powers the stimulation-evoked neuronal activity is produced by oxidative phosphorylation. Furthermore, the lack of a change in the decrease of $\left[\mathrm{O}_{2}\right]$ evoked by neuronal activity when LDH is blocked rules out a transfer of lactate from astrocytes to neurons as a substrate for oxidative phosphorylation to power neuronal activity, at least in the short term.

\section{Effects of oxamate on field potentials}

Despite its lack of effect on the $\left[\mathrm{O}_{2}\right]$ and $[\mathrm{NADH}]$ decreases, oxamate approximately halved the amplitude of the field EPSP and the population spike (Fig. $5 A-D$ ). This is a greater reduction of the population spike than was reported previously by Schurr and Payne (2007). These data might suggest a decrease in charge entry generating the field EPSP and the postsynaptic action potentials, implying a decreased energy requirement in oxamate, which should be reflected in lower oxygen use (contrary to the experimental observations in Fig. 4C,E). However, oxamate also increased the duration of the population spike by a factor of $\sim 1.6$ ( $p=6.2 \times 10^{-5}$, Fig. $5 \mathrm{~A}, \mathrm{E}$; modeling of the superimposed waveforms of the fEPSP and population spike showed that this was too large to result simply from the decrease of the underlying fEPSP) and increased the decay time of the fEPSP by a factor of $\sim 1.5$ (although this did not reach statistical significance; $p=0.1$; Fig. $5 E)$. This suggests that, for reasons unknown, oxamate decreased and prolonged the EPSC, leading to less synchronization of spike timing in different neurons. As a result, although the fEPSP and population spike are decreased and prolonged, the overall $\mathrm{O}_{2}$ use does not change significantly.

Why oxamate alters the EPSC is unclear, but it does not appear to reflect a decrease of energy supply produced by a lack of substrate for oxidative phosphorylation, as applying pyruvate ( $1 \mathrm{~mm}$ ) with oxamate did not prevent the changes in the fEPSP and population spike induced by oxamate (increased insignificantly by $3.0 \pm 8.0 \%, p=0.71$, and $7 \pm 15 \%$, $p=0.71$, respectively; $n=8$, compared to oxamate alone). Oxygen usage was also unaffected by pyruvate supplementation (increased by $10 \pm 7 \%, p=0.19, n=9$, compared to oxamate alone). This suggests that either oxamate or the decrease in lactate concentration has a direct effect on the EPSC. Determining the mechanism of this effect is outside the scope of this study, but there may be contributions from a lactate-mediated decrease in prostaglandin uptake and rise of extracellular prostaglandin concentration (Chan et al., 2002; Gordon et al., 2008), which decreases EPSC amplitude but does not affect decay time (Koch et al., 2010) or from a promotion by lactate of hydroxyl radical formation (Ali et al., 2000) causing a peroxide-mediated increase of $K_{\text {ATP }}$ channel activity (Avshalumov et al., 2005).

\section{Modeling the relationship between the $\left[\mathrm{O}_{2}\right]$ decrease and $\mathrm{O}_{2}$ use}

To use the effect of the drugs in Figure 2 to quantify the $\mathrm{O}_{2}$ used on different subcellular mechanisms, we need to understand how the measured $\left[\mathrm{O}_{2}\right]$ decrease relates to the increase of $\mathrm{O}_{2}$ use evoked by neuronal activity. To establish this, we first estimated the resting $\mathrm{O}_{2}$ usage in the slice, as in the study by Hall and Attwell (2008). The $\mathrm{O}_{2}$ electrode was advanced through the slice to determine the profile of $\left[\mathrm{O}_{2}\right]$ across the unstimulated slice. The results were not significantly different in the stratum pyramidale and stratum radiatum (repeated-measures ANOVA, $p=0.26$, $N=6$; Fig. $6 A$ ), and so were averaged (Fig. $6 B$ ). Next, these data were fitted with steady-state solutions (obtained using the pdepe function in Matlab) of the following diffusion equation:

$$
D \cdot \delta^{2} c / \delta x^{2}=V_{\max } \cdot c /\left(c+K_{\mathrm{m}}\right)+\delta c / \delta t
$$

where $x$ is distance into the slice, $c$ is the concentration of $\mathrm{O}_{2}, D$ is its diffusion coefficient in brain at $37^{\circ} \mathrm{C}\left(1.54 \times 10^{-9} \mathrm{~m}^{2} / \mathrm{s}\right)$ (Ganfield et al., 1970), $K_{\mathrm{m}}=1 \mu \mathrm{M}$ is the $\mathrm{EC}_{50}$ for $\mathrm{O}_{2}$ activating oxidative phosphorylation (Cooper, 2003), and $V_{\max }$ is the maximum rate of oxidative phosphorylation at saturating $\left[\mathrm{O}_{2}\right]$. The boundary condition at the bottom of the slice $(x=300 \mu \mathrm{m}$, resting on the bath chamber) was assumed to be that $\delta c / \delta x=0$. By fixing the value of $\left[\mathrm{O}_{2}\right]$ at the slice surface at its measured value (387 $\pm 47 \mu \mathrm{M}$ in 12 slices), and varying the value of $V_{\max }$, it was found that the data were best fitted with $V_{\max }=0.7 \mathrm{~mm} / \mathrm{min}$ (Fig. $6 \mathrm{~B}$ ), about half the value found previously for acute cerebellar 

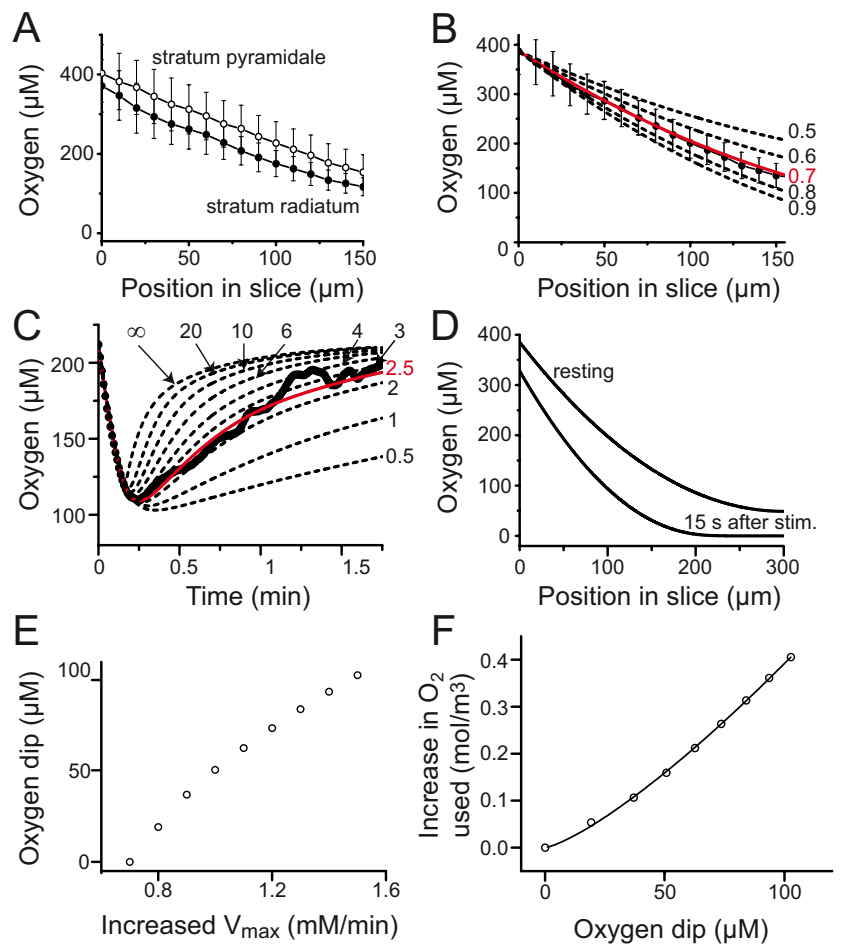

Figure 6. Modeling the $\mathrm{O}_{2}$ consumption of the slice. $A,\left[\mathrm{O}_{2}\right]$ profile across the unstimulated slice in the stratum radiatum and stratum pyramidale ( $N=6$ slices). The slice surface is denoted position 0. $\boldsymbol{B}$, Mean of data in the two regions in $\boldsymbol{A}$ (circles), and theoretical fits for different assumed $V_{\max }$ values for $0_{2}$ consumption (given by each curve), constrained to have the value $387 \mu \mathrm{m}$ at $x=0$. The best fit (in red) is with $V_{\max }=0.7 \mathrm{~mm} / \mathrm{min}$. C, Fitting the $\left[0_{2}\right]$ decrease evoked by stimulation at a position $92 \mu \mathrm{m}$ into the slice. Black circles are the mean control data in $95 \% \mathrm{O}_{2}$ from Figure $3 B$. Each smooth curve is the computed response to an increase of $V_{\max }$ from 0.7 to $1.5 \mathrm{~mm} / \mathrm{min}$, followed by a decay back to $0.7 \mathrm{~mm} / \mathrm{min}$ with the rate constant (in $\mathrm{min}^{-1}$ ) shown by each curve. The best fit (red) is with a rate constant of $2.5 \mathrm{~min}^{-1}$, i.e., a time constant of 0.4 min or 24 s. D. Predicted $\left[0_{2}\right.$ ] profiles across the slice in the resting state and at the peak of the $\mathrm{O}_{2}$ dip following stimulation. $\boldsymbol{E}$, Predicted dependence of the amplitude of the $\left[0_{2}\right]$ transient on the underlying increase of the $V_{\max }$ for $0_{2}$ use. $F$, Predicted relationship between the increase in $\mathrm{O}_{2}$ consumed at the recording site and the size of the $\mathrm{O}_{2}$ dip (the curve is $0_{2}$ consumption $\left./ \mathrm{mm}=7.8 \times(\text { oxygen } \mathrm{dip} / \mathrm{mm})^{1.3}\right)$.

slices but similar to the value found for cultured cerebellar slices (Hall and Attwell, 2008). Having established this value of $V_{\max }$, we next estimated the thickness of the unstirred layer outside the slice, to allow us to compute changes of $\left[\mathrm{O}_{2}\right]$ when $V_{\max }$ was raised by neuronal activity. This was done by solving Equation (1) both within the slice (with $V_{\max }=0.7 \mathrm{~mm} / \mathrm{min}$ ) and outside the slice [with $V_{\max }=0, D$ set to the free solution value of $2.74 \times$ $10^{-9} \mathrm{~m}^{2} / \mathrm{s}$, at $35^{\circ} \mathrm{C}$ (van Stroe and Janssen, 1993), and the $\left[\mathrm{O}_{2}\right]$ in the bulk solution set to $543 \mu \mathrm{M}$ ] (see Materials and Methods), and varying the unstirred layer thickness until the $\left[\mathrm{O}_{2}\right]$ value measured at the surface of the slice $(387 \mu \mathrm{M})$ was reproduced. The unstirred layer was thereby estimated to be $70 \mu \mathrm{m}$ thick. In addition, from the profile of $\left[\mathrm{O}_{2}\right]$ across the slice, it was possible to estimate how deep in the slice the $\mathrm{O}_{2}$ electrode was positioned at the start of the experiments (estimated as $92 \mu \mathrm{m}$ deep, similar to the intended depth of $100 \mu \mathrm{m})$.

With these parameters estimated, we next simulated how the $\left[\mathrm{O}_{2}\right]$ profile across the slice was altered by Schaffer collateral stimulation. To mimic the effect of $\mathrm{Na}^{+}$entry stimulating ATP consumption by the $\mathrm{Na}^{+} / \mathrm{K}^{+}$-ATPase, and hence increasing $\mathrm{O}_{2}$ use, we solved Equation (1) within the slice for a step increase of $V_{\max }$ (throughout the slice) from the $0.7 \mathrm{~mm} / \mathrm{min}$ value derived above to a new higher value for $10 \mathrm{~s}$, followed by an exponential decay back to $0.7 \mathrm{~mm} / \mathrm{min}$. In the unstirred layer outside the slice, Equation (1) was solved with $V_{\max }=0$. The initial values of $\left[\mathrm{O}_{2}\right]$ across the slice were those calculated with $V_{\max }$ set to $0.7 \mathrm{~mm} / \mathrm{min}$ and an unstirred layer thickness of $70 \mu \mathrm{m}$, as above. To reproduce the peak $\left[\mathrm{O}_{2}\right]$ decrease seen in $95 \% \mathrm{O}_{2}$ in Figure $3 \mathrm{~B}$ (at a distance $92 \mu \mathrm{m}$ into the slice), it was necessary to increase $V_{\max }$ within the slice to $1.5 \mathrm{~mm} / \mathrm{min}$ (i.e., an approximate doubling of the $V_{\max }$ ), while to reproduce the decay time course of the $\mathrm{O}_{2}$ transient, the time constant of decay of the $V_{\max }$ increase after stimulation had to be set to $24 \mathrm{~s}$ (a rate constant of $2.5 \mathrm{~min}^{-1}$; Fig. $6 \mathrm{C}$ ). The resulting profile of $\left[\mathrm{O}_{2}\right]$ through the slice at the peak of the response is shown in Figure $6 \mathrm{D}$. Although neuronal activity may not really produce an immediate and constant increase in the $V_{\max }$ for $\mathrm{O}_{2}$ use throughout the stimulation period, this assumed time course for the increase in $V_{\max }$ during activity, and the subsequent exponential decrease, reproduced reasonably well the measured time course of the $\left[\mathrm{O}_{2}\right]$ transient at a distance $92 \mu \mathrm{m}$ into the slice. The calculated $V_{\max }$ of $1.5 \mathrm{~mm} / \mathrm{min}$ is similar to the cerebral metabolic rate for oxygen measured in vivo in anesthetized rats (Ichord et al., 2001; Zhu et al., 2007) and about one-third of the value calculated from glucose usage in unanaesthetized rats (Sokoloff et al., 1977), implying that the neuronal activity that we are evoking is similar to that normally studied in anesthetized animals, but below the maximum level occurring in resting animals in vivo. This is probably not due to our use of P21 (rather than adult) rats, because the cerebral metabolic rate for oxygen is not significantly different at these two ages (Dahlquist and Persson, 1976). Presumably, therefore, we are not stimulating sufficient axons to generate activity matching that occurring in vivo.

With the response in control solution reasonably well reproduced, we then investigated the effect on the predicted $\left[\mathrm{O}_{2}\right]$ transient of reducing the increase of $V_{\max }$, to mimic the effect of reducing the activity-evoked increase of $\mathrm{O}_{2}$ use with glutamate receptor blockers or $\mathrm{Cd}^{2+}$. The aim was to assess how the amplitude of the $\left[\mathrm{O}_{2}\right]$ transient was related to the change of $V_{\max }$ that generated it. For this analysis, we assumed that there was no change in the time constant with which the $V_{\max }$ decreased after activity. The resulting relationship between the amplitude of the $\left[\mathrm{O}_{2}\right]$ decrease evoked by activity and the underlying increase of $V_{\max }$ was roughly linear, but with a decrease in slope at larger values of $V_{\max }$ (Fig. $6 E$ ). The nonlinearity in this relationship results from the fact that, in the depth of the slice, the predicted $\left[\mathrm{O}_{2}\right]$ becomes comparable to the $\mathrm{K}_{\mathrm{m}}$ for $\mathrm{O}_{2}$ use by mitochondria (Fig. $6 D$ ), rendering Equation (1) nonlinear [unlike for $c \gg K_{\mathrm{m}}$ when Eq. (1) becomes $D \cdot \delta^{2} c / \delta x^{2}-\delta c / \delta t=V_{\max }$ so that changes of $c$ are proportional to changes of $\left.V_{\max }\right]$. When we calculated the increased $\mathrm{O}_{2}$ usage at the position of the $\mathrm{O}_{2}$ electrode as (see Eq. 1) $V_{\max } c /\left(c+K_{\mathrm{m}}\right)$ and integrated over a 4 min period from when the $10 \mathrm{~s}$ stimulation started, this was found to vary approximately as the amplitude of the $\mathrm{O}_{2}$ dip raised to the power 1.3 (Fig. $6 \mathrm{~F}$ ). Using this relationship, the changes in the amplitude of the $\mathrm{O}_{2}$ dip measured in Figure 2 can be converted to relative $\mathrm{O}_{2}$ usage on different mechanisms (see below, The fraction of $\mathrm{O}_{2}$ use on the subcellular mechanisms mediating information processing).

A similar analysis showed that (in the absence of blocking drugs) the stimulation-evoked $\mathrm{O}_{2}$ usage in $20 \% \mathrm{O}_{2}$ was $77 \%$ of that occurring in $95 \% \mathrm{O}_{2}$. This $23 \%$ decrease is approximately as expected, given the $38 \%$ decrease of fEPSP amplitude and $15 \%$ decrease of population spike amplitude seen in $20 \% \mathrm{O}_{2}$ (Fig. $3 A$ ). Thus, at an approximately physiological $\mathrm{O}_{2}$ level, almost as much ATP is made by oxidative phosphorylation as occurs in $95 \% \mathrm{O}_{2}$.

Finally, we examined the sensitivity of the $\mathrm{O}_{2}$ electrode for detecting $\mathrm{O}_{2}$ usage at different spatial locations, by simulating in two dimensions (into the depth of the slice and across the slice 
from the stratum radiatum and stratum lacunosum moleculare to the stratum oriens and alveus) the change in $\mathrm{O}_{2}$ concentration that occurs. Starting from the steady-state solution to Equation 1 with $V_{\max }=0.7 \mathrm{~mm} / \mathrm{min}$, we simulated the $\mathrm{O}_{2}$ concentration change occurring when $V_{\max }$ was increased for $10 \mathrm{~s}$ to $1.5 \mathrm{~mm} /$ min, either solely in the stratum radiatum and stratum lacunosum moleculare (the combined width of which was measured as $258 \mu \mathrm{m}$ in 6 slices) or solely in the stratum pyramidale, stratum oriens, and alveus (combined width measured as $184 \mu \mathrm{m}$ ). MathCad was used to solve by Euler's method the two-dimensional diffusion equation with $\mathrm{O}_{2}$ consumption:

$$
D \cdot\left(\delta^{2} c / \delta x^{2}+\delta^{2} c / \delta y^{2}\right)=V_{\max }(x, y, t) \cdot c /\left(c+K_{\mathrm{m}}\right)+\delta c / \delta t
$$

A distance step of $2 \mu \mathrm{m}$ in each direction and a time step of 0.25 ms were used, after checking that $1 \mu \mathrm{m}$ and $0.1 \mathrm{~ms}$ steps gave negligibly different results. At the location we placed the $\mathrm{O}_{2}$ electrode $(92$ $\mu \mathrm{m}$ into the slice, at a distance $30 \mu \mathrm{m}$ into the stratum radiatum) (see above), increasing $V_{\max }$ to $1.5 \mathrm{~mm} / \mathrm{min}$ throughout the stratum radiatum and stratum lacunosum moleculare decreased $\left[\mathrm{O}_{2}\right]$ by 61 $\mu \mathrm{M}$, while increasing $V_{\max }$ to $1.5 \mathrm{~mm} / \mathrm{min}$ throughout the alveus, stratum oriens, and stratum pyramidale decreased $\left[\mathrm{O}_{2}\right]$ by $35 \mu \mathrm{M}$ (i.e., $57 \%$ of $61 \mu \mathrm{M}$ ). Since the alveus/stratum oriens/stratum pyramidale is only $71 \%$ of the width of the stratum radiatum/stratum lacunosum moleculare (so the total increased $\mathrm{O}_{2}$ use was only $71 \%$ of that assumed for the simulation when there was increased $\mathrm{O}_{2}$ use in the stratum radiatum/stratum lacunosum moleculare), this means that the sensitivity to $V_{\max }$ increases in the alveus/stratum oriens/stratum pyramidale is $20 \%(1-57 \% / 71 \%)$ less than for $V_{\max }$ changes in the stratum radiatum/stratum lacunosum moleculare. This might be thought to result in an underestimate of the $\mathrm{O}_{2}$ use on postsynaptic action potentials, since in pyramidal cells these will use $\mathrm{O}_{2}$ in the alveus, stratum oriens, and stratum pyramidale. However, the underestimate will be $<20 \%$ (and is ignored in what follows), because some of the $\mathrm{O}_{2}$ use on postsynaptic action potentials will occur in interneurons in the stratum radiatum.

To deduce the relationship between $\left[\mathrm{O}_{2}\right]$ decrease and $\mathrm{O}_{2}$ use in the experiments of Figure $2 \mathrm{H}$ using glutamate superfusion, simulations similar to those described for Figure $6 \mathrm{~F}$ were performed for the longer period of $\mathrm{O}_{2}$ usage evoked by glutamate superfusion, which predicted that $\mathrm{O}_{2}$ usage would vary as the amplitude of the $\mathrm{O}_{2}$ dip raised to the power 1.5.

\section{The fraction of $\mathrm{O}_{2}$ use on the subcellular mechanisms mediating information processing}

Correcting the $63 \%$ reduction in the size of the stimulationevoked $\left[\mathrm{O}_{2}\right]$ transient that is produced by NBQX + AP5 in Figure $2 \mathrm{E}$, for the nonlinearity of the relationship between $\left[\mathrm{O}_{2}\right]$ dip and $\mathrm{O}_{2}$ consumption that is shown in Figure $6 \mathrm{~F}$, we calculated that postsynaptic currents and postsynaptic action potentials are responsible for $72 \%$ of the $\mathrm{O}_{2}$ usage. Similarly the $82 \%$ block of the $\mathrm{O}_{2}$ transient produced by $\mathrm{Cd}^{2+}$, when corrected for the nonlinearity of Figure $6 \mathrm{~F}$, implies that $89 \%$ of the $\mathrm{O}_{2}$ is used on mechanisms that are blocked by $\mathrm{Cd}^{2+}$. The difference between the $72 \%$ reduction of the $\left[\mathrm{O}_{2}\right]$ usage produced by NBQX + AP 5 and the $89 \%$ reduction produced by $\mathrm{Cd}^{2+}$ implies that events that are not triggered by activation of postsynaptic glutamate ionotropic receptors but are triggered by presynaptic $\mathrm{Ca}^{2+}$ entry (i.e., pumping out presynaptic $\mathrm{Ca}^{2+}$, vesicle release and refilling, actions of mGluRs, and transmitter uptake) consume $17 \%$ of the $\mathrm{O}_{2}$. The difference between the $89 \%$ reduction of $\left[\mathrm{O}_{2}\right]$ usage by $\mathrm{Cd}^{2+}$ and the complete block produced by TTX implies that $11 \%$
A
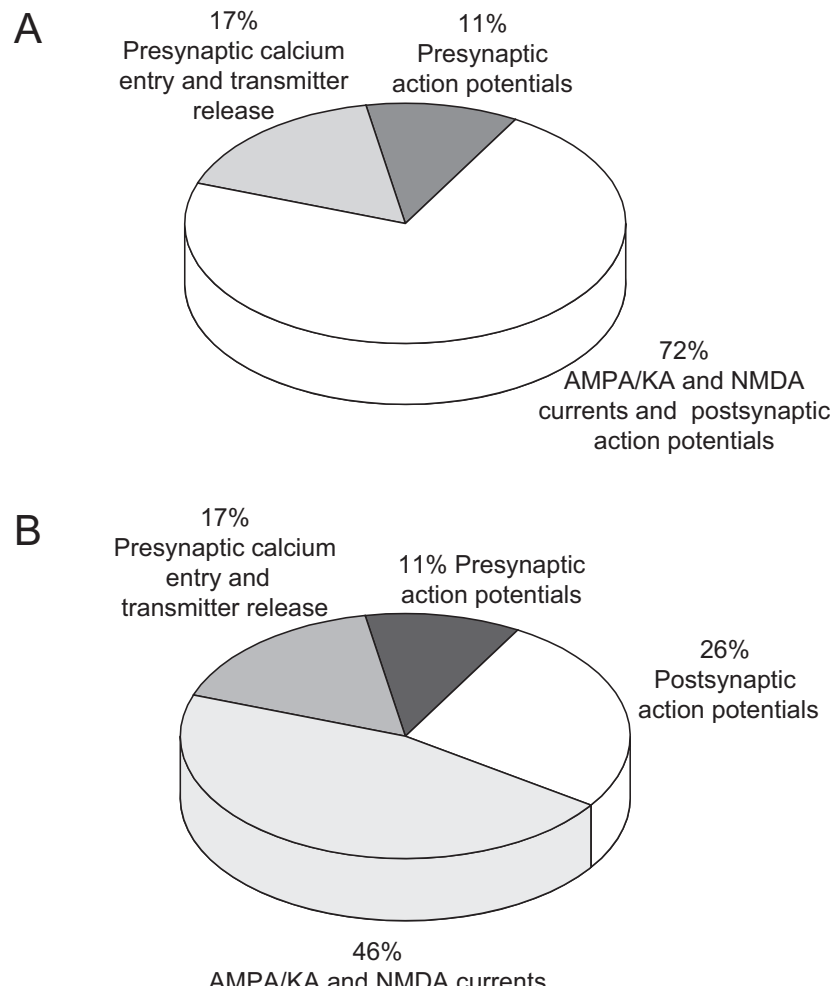

AMPA/KA and NMDA currents

Figure 7. The distribution of $\mathrm{O}_{2}$ use across different subcellular processes. $A$, The $\mathrm{O}_{2}$ use on AMPA/KA and NMDA receptor currents and postsynaptic action potentials (blocked by $\mathrm{NBQX}+\mathrm{AP5})$; on presynaptic $\mathrm{Ca}^{2+}$ entry, vesicle release and refilling, mGluR activity, and transmitter uptake (blocked by $\mathrm{Cd}^{2+}$ but not by NBQX); and on presynaptic action potentials (blocked by TTX but not by $\mathrm{Cd}^{2+}$ ). $\boldsymbol{B}$, The $\mathrm{O}_{2}$ use on different subcellular mechanisms derived from $\boldsymbol{A}$ by using the analysis of $\mathrm{O}_{2}$ use on postsynaptic glutamate-gated currents and action potentials derived from experiments applying glutamate in Figure 2 I. Activity-induced ATP use on mGluRs and astrocytes are ignored, but were estimated by Attwell and Laughlin (2001) to be $\sim 2 \%$ and $<7 \%$ of that in neurons, respectively.

of the $\mathrm{O}_{2}$ usage is on presynaptic action potentials. This division of $\mathrm{O}_{2}$ usage is shown in Figure $7 A$.

With the split of energy use between presynaptic and postsynaptic mechanisms given above, we can use the data in Figure 2 I to estimate how the $\mathrm{O}_{2}$ consumption on postsynaptic mechanisms is divided between glutamate-gated ion channels and action potentials, if we assume that glutamate-evoked energy use on mGluRs and in astrocytes is small [Attwell and Laughlin (2001) estimated that, for each vesicle of glutamate released, the ATP use on mGluRs was only $2.2 \%$ of that on ionotropic glutamate receptors, and the ATP use in astrocytes was only $6.8 \%$ of that in neurons or less if ATP use on action potentials was included]. To do this, we assume that the dependence of action potential firing rate on mean glutamate-gated current is the same when action potentials are evoked by superfusing glutamate (as in Fig. 2I) and by activating the Schaffer collateral input (as in Fig. $2 E$ ), so that the relative magnitudes of the ion influxes through glutamategated channels and through voltage-gated $\mathrm{Na}^{+}$channels are the same in both situations. With this assumption, the $29 \%$ reduction of the $\mathrm{O}_{2}$ dip seen in Figure $2 \mathrm{I}$ was transformed through a relationship like that in Figure $6 F$ (see above). This transformation predicted that the $\mathrm{O}_{2}$ use attributed to postsynaptic mechanisms above is split between postsynaptic glutamategated currents and postsynaptic action potentials in a ratio of 64 to $36 \%$, implying that $46 \%$ (i.e., $72 \% \times 0.64$ ) of the $\mathrm{O}_{2}$ use evoked by Schaffer collateral stimulation is on postsynaptic 
currents, and $26 \%(72 \% \times 0.36)$ is on postsynaptic action potentials. Combining these $\mathrm{O}_{2}$ usages, with those for presynaptic action potentials and nonpostsynaptic events downstream of presynaptic $\mathrm{Ca}^{2+}$ entry in Figure $7 A$, gives the division of $\mathrm{O}_{2}$ use shown in Figure $7 B$.

\section{NADH usage}

Knowing the amount of oxygen used during Schaffer collateral stimulation allows us to calculate the NADH turnover that must be occurring. From the curve fit to Figure $6 \mathrm{~F}$ and the mean oxygen dip of $118 \mu \mathrm{M}$ (Fig. 1), $0.485 \mathrm{~mm} \mathrm{O}_{2}$ can be calculated to be consumed following Schaffer collateral stimulation. Ten NADH molecules are used for each $6 \mathrm{O}_{2}$ molecules consumed (Fig. $1 \mathrm{H}$ ), implying a usage of $0.808 \mathrm{~mm} \mathrm{NADH}$. Importantly, the resting level of $\mathrm{NADH}$ in hippocampus is only $0.057 \mu \mathrm{mol} / \mathrm{g}$ tissue (Klaidman et al., 1995), or $60 \mu \mathrm{M}$ assuming a density of $1.05 \mathrm{~g} / \mathrm{ml}$. Using this resting NADH concentration, the measured $1.4 \%$ decrease of $[\mathrm{NADH}]$ (Fig. $1 \mathrm{~F}$ ) implies that $[\mathrm{NADH}]$ decreases by only $0.84 \mu \mathrm{M}$, underrepresenting the absolute usage of NADH by three orders of magnitude. High rates of both NADH production and consumption must, therefore, be occurring during the $\mathrm{NADH}$ dip period and, since oxygen is still being used (Fig. 3D), during the overshoot. As the NADH dip and overshoot poorly reflect the actual amounts of $\mathrm{NADH}$ used and generated, they cannot be used to quantify the amount of oxidative phosphorylation or glycolysis occurring. For this reason, we limit our interpretation of the NADH changes to arguing that the existence of a dip means that there is a larger relative contribution of oxidative phosphorylation than glycolysis to ATP production following neuronal stimulation (see above).

\section{Discussion}

Our data lead to three major conclusions for the powering of neuronal activity. First, the majority of the ATP powering increases of neuronal activity is produced by oxidative phosphorylation. Second, the main mechanisms contributing to information processing, i.e., presynaptic action potentials, transmitter release, postsynaptic currents, and postsynaptic action potentials, are all powered by ATP generated from oxidative phosphorylation. Third, the simplest version of the astrocyte-neuron lactate shuttle hypothesis, in which neuronal activity initially triggers ATP generation by glycolysis in astrocytes which then release lactate to rapidly power neuronal oxidative phosphorylation, is not consistent with our data.

\section{The majority of ATP is generated by oxidative phosphorylation}

Neuronal activity evoked by stimulating the Schaffer collaterals generated an initial decrease in both extracellular $\left[\mathrm{O}_{2}\right]$ and intracellular $[\mathrm{NADH}]$ (Fig. 1). These decreases were also seen when a physiological oxygen level was produced in the slice by superfusion with solution gassed with $20 \%$ oxygen (Fig. 3 ), and they still occurred when lactate dehydrogenase was blocked with oxamate (Fig. 4). The fact that a decrease of [NADH] is seen, averaged over the neurons and astrocytes in the slice, with lactate dehydrogenase blocked to prevent interconversion of pyruvate and lactate, implies that at least $62 \%$ of the increase in ATP production which occurs in the slice to power the increase in neuronal activity is generated by oxidative phosphorylation (see Results).

As reviewed in the introduction, the association of glycolytic enzymes with ion pumps, the apparently larger fractional increase of glucose uptake than of oxygen uptake in response to neuronal activity (Fox et al., 1988) [but see the study by Madsen et al. (1999), who found a less significant decrease of the $\mathrm{O}_{2}$ : glucose utilization ratio], and the notion that neurons regulate their energy supply by initially increasing glycolysis in astrocytes, all suggested that neuronal activity was initially powered by glycolysis. Our data show, on the contrary, that oxidative phosphorylation is responsible for most of the increase in ATP production. In a methodologically very different approach, magnetic resonance imaging and spectroscopy have recently suggested a similar conclusion (Lin et al., 2010).

The change of $\mathrm{O}_{2}$ concentration evoked by $10 \mathrm{~s}$ of $20 \mathrm{~Hz}$ stimulation of the Schaffer collaterals could be predicted if the rate of $\mathrm{O}_{2}$ consumption approximately doubled at the start of stimulation and decayed exponentially after the stimulation with a time constant of $24 \mathrm{~s}$ (Fig. 6). Although we assumed an immediate rise in $\mathrm{O}_{2}$ consumption in our model, in reality it is likely that the rise is slower (set by the rate of rise of $\left[\mathrm{Na}^{+}\right]_{\mathrm{i}}$ and $\left[\mathrm{K}^{+}\right]_{\mathrm{o}}$, which stimulate sodium pump activity), and that the kinetics of the fall of $\left[\mathrm{O}_{2}\right]$ are set by diffusive equilibration with the bulk solution and are not critically dependent on the rate at which $\mathrm{O}_{2}$ usage turns on. The recovery of $\left[\mathrm{O}_{2}\right]$ use after stimulation is much slower than is predicted if metabolic demand were removed immediately when the stimulation stopped (Fig. 6C), and presumably the $24 \mathrm{~s}$ decay of $\mathrm{O}_{2}$ use that we derived for $95 \% \mathrm{O}_{2}$ reflects the time needed for the sodium pump to restore the ion gradients across the cell membranes. In $20 \% \mathrm{O}_{2}$, the decay of $\mathrm{O}_{2}$ use was greatly prolonged (Fig. $3 B$ ), implying that the local $\mathrm{O}_{2}$ level in the brain will influence the time scale on which neurons can reinstate their ion gradients after activity.

After the initial decrease of $\left[\mathrm{O}_{2}\right]$ and $[\mathrm{NADH}]$, there was an increase of $[\mathrm{NADH}]$ above its prestimulus level, which may reflect increased $\mathrm{NADH}$ production either by glycolysis or by an increased activity of the TCA cycle. The [NADH] overshoot overlaps in time with the prolonged decrease in $\left[\mathrm{O}_{2}\right]$ evoked by stimulation (Fig. 3D) and so occurs at a time when oxidative phosphorylation is increased.

\section{The distribution of $\mathrm{O}_{2}$ consumption on different subcellular mechanisms}

Using pharmacological agents to isolate different subcellular mechanisms contributing to neuronal activity, we demonstrated that presynaptic activity, transmitter release and recycling, and postsynaptic activity are all powered at least partly by oxidative phosphorylation (Fig. 2). Using the response to superfused glutamate, in the presence and absence of TTX, to separate energy use on postsynaptic glutamate-gated currents and on action potentials, we estimate that presynaptic action potentials consume $\sim 11 \%$; presynaptic $\mathrm{Ca}^{2+}$ entry, transmitter release/recycling, and mGluR activity consume $\sim 17 \%$; postsynaptic currents use $\sim 46 \%$; and postsynaptic action potentials consume $\sim 26 \%$ of the $\mathrm{O}_{2}$ (Fig. $7 B$ ), so presynaptic and postsynaptic action potentials together use $37 \%$ of the $\mathrm{O}_{2}$.

Thus, the present findings provide evidence against the hypotheses that most energy is used presynaptically (Jueptner and Weiller, 1995) or that action potential propagation operates mainly anaerobically (Lecoq et al., 2009). On the other hand, they support findings showing that a large fraction of energy consumption is postsynaptically driven (Attwell and Laughlin, 2001; Offenhauser et al., 2005).

The energy budget of Attwell and Laughlin (2001) for rat cortex predicts the energy used on different components of neuronal signaling. From their Figure $3 A$, ignoring ATP used on the resting potential and reducing the action potential energy use by a factor of 3.08 to compensate for the fact that mammalian neurons use 3.08 -fold less energy (per membrane area) on action potentials 
than do the squid action potentials that the Attwell and Laughlin (2001) budget was based on (Alle et al., 2009), action potentials are expected to use $28 \%$, presynaptic $\mathrm{Ca}^{2+}$ entry, transmitter release/recycling, and mGluRs $11 \%$, and postsynaptic currents $61 \%$ of the stimulation-evoked ATP consumption. This is in reasonable agreement with Figure $7 B$, considering that we are studying hippocampus and not cortex, and that the relative contributions of the different mechanisms may vary with stimulus frequency (e.g., due to AMPA receptor desensitization or NMDA receptors experiencing less $\mathrm{Mg}^{2+}$ block during high-frequency stimulation).

\section{Implications for the astrocyte-neuron lactate shuttle hypothesis}

The astrocyte-neuron lactate shuttle hypothesis assumes that astrocytes convert glycolytically derived pyruvate to lactate using lactate dehydrogenase, before exporting it to neurons where it is converted back to pyruvate, again by lactate dehydrogenase, and then enters the TCA cycle as fuel for oxidative phosphorylation (Fig. $1 \mathrm{H}$ ). On this basis, one might expect blocking lactate dehydrogenase to abolish or reduce the increase in $\mathrm{O}_{2}$ consumption evoked by neuronal activity. We found, however, that the LDH blocker oxamate had no effect on the initial decrease in $\left[\mathrm{O}_{2}\right]$ or [NADH] that is evoked by Schaffer collateral stimulation (Fig. 4). We conclude that the increase in oxidative phosphorylation that generates ATP to power an increase of neuronal activity does not require lactate transfer from astrocytes.

It is worth highlighting that, at P21, rats express their highest levels of the monocarboxylate transporter responsible for transporting lactate into neurons (MCT2), with expression decreasing thereafter (Prins, 2008), and increased MCT2 expression is proposed to lead to increased lactate shuttle activity (Pellerin and Magistretti, 2011). If neuronal energy metabolism does not depend on lactate transfer at P21, therefore, it is unlikely to contribute at older ages, when MCT2 expression is lower.

Apparently contradicting our findings, Schurr and Payne (2007) and Schurr and Gozal (2011) found that inhibiting LDH with malonate or oxamate decreased neuronal function when hippocampal slices were maintained in glucose or lactate, but that neuronal function could be preserved by superfusing pyruvate, supporting the idea of a lactate shuttle. However, effects of malonate and oxamate on neuronal function were only seen after $30-45$ min or after excitotoxic challenge. Furthermore, and crucially, oxidative phosphorylation was not monitored by recording oxygen level, so the interpretation of the data presented in terms of altered ATP production by mitochondria is not secure. We suggest that, while lactate may be important for long-term functioning of the slice, it is not required for the short-term increase in oxidative phosphorylation that occurs after an increase in neuronal activity. This interpretation is consistent with a recent review (Mangia et al., 2011) of contradictory modeling studies that disagreed over whether lactate passes from astrocytes to neurons or from neurons to astrocytes. Mangia et al. (2011) concluded that, whichever way lactate moves, its contribution to oxidative phosphorylation is small (Dienel and Cruz, 2008). An export of lactate from astrocytes to neurons was suggested previously to be essential for hippocampal synaptic plasticity (Suzuki et al., 2011). Our data suggest that this effect may be mediated by lactate functioning as a signaling molecule (Song and Routh, 2005; Shimizu et al., 2007; Bezzi and Volterra, 2011), rather than as a metabolic substrate.

\section{References}

Akgören N, Fabricius M, Lauritzen M (1994) Importance of nitric oxide for local increases of blood flow in rat cerebellar cortex during electrical stimulation. Proc Natl Acad Sci U S A 91:5903-5907.

Ali MA, Yasui F, Matsugo S, Konishi T (2000) The lactate-dependent enhancement of hydroxyl radical generation by the Fenton reaction. Free Radic Res 32:429-438.

Alle H, Roth A, Geiger JR (2009) Energy-efficient action potentials in hippocampal mossy fibers. Science 325:1405-1408.

Amato A, Ballerini L, Attwell D (1994) Intracellular pH changes produced by glutamate uptake in rat hippocampal slices. J Neurophysiol 72:1686-1696.

Attwell D, Laughlin SB (2001) An energy budget for signaling in the grey matter of the brain. J Cereb Blood Flow Metab 21:1133-1145.

Aubin JE (1979) Autofluorescence of viable cultured mammalian cells. J Histochem Cytochem 27:36-43.

Avshalumov MV, Chen BT, Koós T, Tepper JM, Rice ME (2005) Endogenous hydrogen peroxide regulates the excitability of midbrain dopamine neurons via ATP-sensitive potassium channels. J Neurosci 25:4222-4231.

Barros LF, Deitmer JW (2010) Glucose and lactate supply to the synapse. Brain Res Rev 63:149-159.

Bezzi P, Volterra A (2011) Astrocytes: powering memory. Cell 144: 644-645.

Blinova K, Levine RL, Boja ES, Griffiths GL, Shi ZD, Ruddy B, Balaban RS (2008) Mitochondrial NADH fluorescence is enhanced by complex I binding. Biochemistry 47:9636-9645.

Brazitikos PD, Pournaras CJ, Munoz JL, Tsacopoulos M (1993) Microinjection of L-lactate in the preretinal vitreous induces segmental vasodilation in the inner retina of miniature pigs. Invest Ophthalmol Vis Sci 34:1744-1752.

Brennan AM, Connor JA, Shuttleworth CW (2006) NAD(P)H fluorescence transients after synaptic activity in brain slices: predominant role of mitochondrial function. J Cereb Blood Flow Metab 26:1389-1406

Caesar K, Thomsen K, Lauritzen M (2003) Dissociation of spikes, synaptic activity, and activity-dependent increments in rat cerebellar blood flow by tonic synaptic inhibition. Proc Natl Acad Sci U S A 100:16000-16005.

Chan BS, Endo S, Kanai N, Schuster VL (2002) Identification of lactate as a driving force for prostanoid transport by prostaglandin transporter PGT. Am J Physiol Renal Physiol 282:F1097-F1102.

Chance B, Williams GR (1955) Respiratory enzymes in oxidative phosphorylation. III. The steady state. J Biol Chem 217:409-427.

Contreras L, Satrústegui J (2009) Calcium signaling in brain mitochondria: interplay of malate aspartate NADH shuttle and calcium uniporter/mitochondrial dehydrogenase pathways. J Biol Chem 284:7091-7099.

Cooper CE (2003) Competitive, reversible, physiological? Inhibition of mitochondrial cytochrome oxidase by nitric oxide. IUBMB Life 55:591-597.

Dahlquist G, Persson B (1976) The rate of cerebral utilization of glucose, ketone bodies and oxygen: a comparative in vivo study of infant and adult rats. Pediat Res 10:910-917.

Dienel GA, Cruz NF (2008) Imaging brain activation: simple pictures of complex biology. Ann N Y Acad Sci 1147:139-170.

Dings J, Meixensberger J, Jäger A, Roosen K (1998) Clinical experience with 118 brain tissue oxygen partial pressure catheter probes. Neurosurgery 43:1082-1095.

Dubinsky WP, Mayorga-Wark O, Schultz SG (1998) Colocalization of glycolytic enzyme activity and KATP channels in basolateral membrane of Necturus enterocytes. Am J Physiol 275:C1653-C1659.

Duchen MR (1992) $\mathrm{Ca}^{2+}$-dependent changes in the mitochondrial energetics in single dissociated mouse sensory neurons. Biochem J 283:41-50.

Fox PT, Raichle ME, Mintun MA, Dence C (1988) Nonoxidative glucose consumption during focal physiologic neural activation. Science 241:462-464

Ganfield RA, Nair P, Whalen WJ (1970) Mass transfer, storage, and utilization of $\mathrm{O}_{2}$ in cat cerebral cortex. Am J Physiol 219:814-821.

Gellerich FN, Gizatullina Z, Arandarcikaite O, Jerzembek D, Vielhaber S, Seppet E, Striggow F (2009) Extramitochondrial $\mathrm{Ca}^{2+}$ in the nanomolar range regulates glutamate-dependent oxidative phosphorylation on demand. PLoS One 4:e8181.

Gellerich FN, Gizatullina Z, Trumbeckaite S, Nguyen HP, Pallas T, Arandarcikaite O, Vielhaber S, Seppet E, Striggow F (2010) The regulation of OXPHOS by extramitochondrial calcium. Biochim Biophys Acta 1797:1018-1027. 
Gjedde A (2005) The pathways of oxygen in brain. I. Delivery and metabolism of oxygen. Adv Exp Med Biol 566:269-275.

Gordon GR, Choi HB, Rungta RL, Ellis-Davies GC, MacVicar BA (2008) Brain metabolism dictates the polarity of astrocyte control over arterioles. Nature 456:745-749.

Gunter TE, Yule DI, Gunter KK, Eliseev RA, Salter JD (2004) Calcium and mitochondria. FEBS Lett 567:96-102.

Hall CN, Attwell D (2008) Assessing the physiological concentration and targets of nitric oxide in brain tissue. J Physiol 586:3597-3615.

Hyder F, Patel AB, Gjedde A, Rothman DL, Behar KL, Shulman RG (2006) Neuronal-glial glucose oxidation and glutamatergic-GABAergic function. J Cereb Blood Flow Metab 26:865-877.

Ichord RN, Johnston MV, Traystman RJ (2001) MK801 decreases glutamate release and oxidative metabolism during hypoglycemic coma in piglets. Brain Res Dev Brain Res 128:139-148.

Jang IS, Ito Y, Akaike N (2005) Feed forward facilitation of glutamate release by presynaptic $\mathrm{GABA}_{\mathrm{A}}$ receptors. Neuroscience 135:737-748.

Jueptner M, Weiller C (1995) Does measurement of regional cerebral blood flow reflect synaptic activity? Implications for PET and fMRI. Neuroimage 2:148-156.

Kasischke KA, Vishwasrao HD, Fisher PJ, Zipfel WR, Webb WW (2004) Neural activity triggers neuronal oxidative metabolism followed by astrocytic glycolysis. Science 305:99-103.

Kety SS (1957) The general metabolism of the brain in vivo. In: Metabolism of the nervous system (Richter D, ed), pp 221-237. London: Pergamon.

Klaidman LK, Leung AC, Adams JD (1995) High-performance liquid chromatography analysis of oxidized and reduced pyridine dinucleotides in specific brain regions. Analyt Biochem 228:312-317.

Knull HR (1978) Association of glycolytic enzymes with particulate fractions from nerve endings. Biochim Biophys Acta 522:1-9.

Koch H, Huh SE, Elsen FP, Carroll MS, Hodge RD, Bedogni F, Turner MS, Hevner RF, Ramirez JM (2010) Prostaglandin $E_{2}$-induced synaptic plasticity in neocortical networks of organotypic slice cultures. J Neurosci 30:11678-11687.

Lecoq J, Tiret P, Najac M, Shepherd GM, Greer CA, Charpak S (2009) Odorevoked oxygen consumption by action potential and synaptic transmission in the olfactory bulb. J Neurosci 29:1424-1433.

Leutgeb JK, Leutgeb S, Moser MB, Moser EI (2007) Pattern separation in the dentate gyrus and CA3 of the hippocampus. Science 315:961-966.

Li J, Iadecola C (1994) Nitric oxide and adenosine mediate vasodilation during functional activation in cerebellar cortex. Neuropharmacol 33:1453-1461.

Lin AL, Fox PT, Hardies J, Duong TQ, Gao JH (2010) Nonlinear coupling between cerebral blood flow, oxygen consumption, and ATP production in human visual cortex. Proc Natl Acad Sci U S A 107:8446-8451.

Lipton P, Robacker K (1983) Glycolysis and brain function: $[\mathrm{K}+]_{\mathrm{o}}$ stimulation of protein synthesis and $\mathrm{K}^{+}$uptake require glycolysis. Fed Proc 42:2875-2880.

Lu M, Holliday LS, Zhang L, Dunn WA Jr, Gluck SL (2001) Interaction between aldolase and vacuolar $\mathrm{H}^{+}$-ATPase: evidence for direct coupling of glycolysis to the ATP-hydrolyzing proton pump. J Biol Chem 276: 30407-30413.

Madsen PL, Cruz NF, Sokoloff L, Dienel GA (1999) Cerebral oxygen/glucose ratio is low during sensory stimulation and rises above normal during recovery: excess glucose consumption during stimulation is not accounted for by lactate efflux from or accumulation in brain tissue. J Cereb Blood Flow Metab 19:393-400.

Magistretti PJ, Pellerin L, Rothman DL, Shulman RG (1999) Energy on demand. Science 283:496-497.

Malonek D, Grinvald A (1996) Interactions between electrical activity and cortical microcirculation revealed by imaging spectroscopy: implications for functional brain mapping. Science 272:551-554.

Mangia S, DiNuzzo M, Giove F, Carruthers A, Simpson IA, Vannucci SJ (2011) Response to 'comment on recent modeling studies of astrocyteneuron metabolic interactions': much ado about nothing. J Cereb Blood Flow Metab 31:1346-1353.

Martin-Requero A, Ayuso MS, Parrilla R (1986a) Interaction of oxamate with the gluconeogenic pathway in liver. Arch Biochem Biophys 246:114-127.

Martin-Requero A, Ayuso MS, Parrilla R (1986b) Rate-limiting steps for hepatic gluconeogenesis. Mechanism of oxamate inhibition of mitochondrial pyruvate metabolism. J Biol Chem 261:13973-13978.
Mathiesen C, Caesar K, Thomsen K, Hoogland TM, Witgen BM, Brazhe A, Lauritzen M (2011) Activity-dependent increases in local oxygen consumption correlate with postsynaptic currents in the mouse cerebellum in vivo. J Neurosci 31:18327-18337.

Mercer RW, Dunham PB (1981) Membrane-bound ATP fuels the $\mathrm{Na} / \mathrm{K}$ pump. Studies on membrane-bound glycolytic enzymes on inside-out vesicles from human red cell membranes. J Gen Physiol 78:547-568.

Offenhauser N, Thomsen K, Caesar K, Lauritzen M (2005) Activity induced tissue oxygenation changes in rat cerebellar cortex: interplay of postsynaptic activation and blood flow. J Physiol 565:279-294.

Ogawa S, Lee TM, Barrere B (1993) The sensitivity of magnetic resonance image signals of a rat brain to changes in the cerebral venous blood oxygenation. Magn Reson Med 29:205-210.

Paul RJ, Bauer M, Pease W (1979) Vascular smooth muscle: aerobic glycolysis linked to sodium and potassium transport processes. Science 206: 1414-1416.

Paul RJ, Hardin CD, Raeymaekers L, Wuytack F, Casteels R (1989) Preferential support of $\mathrm{Ca} 2+$ uptake in smooth muscle plasma membrane vesicles by an endogenous glycolytic cascade. FASEB J 3:2298-2301.

Pellerin L, Bouzier-Sore AK, Aubert A, Serres S, Merle M, Costalat R, Magistretti PJ (2007) Activity-dependent regulation of energy metabolism by astrocytes: an update. Glia 55:1251-1262.

Pellerin L, Magistretti PJ (1994) Glutamate uptake into astrocytes stimulates aerobic glycolysis: a mechanism coupling neuronal activity to glucose utilization. Proc Natl Acad Sci U S A 91:10625-10629.

Pellerin L, Magistretti PJ (2011) Sweet sixteen for ANLS. J Cereb Blood Flow Metab. Advance online publication. Retrieved October 26, 2011. doi: $10.1038 / j \mathrm{cbfm} .2011 .149$.

Prins ML (2008) Cerebral metabolic adaptation and ketone metabolism after brain injury. J Cereb Blood Flow Metab 28:1-16.

Rej R (1979) Measurement of aspartate aminotransferase activity: effects of oxamate. Clin Chem 25:555-559.

Schurr A, Gozal E (2011) Aerobic production and utilization of lactate satisfy increased energy demands upon neuronal activation in hippocampal slices and provide neuroprotection against oxidative stress. Front Pharmacol 2:96.

Schurr A, Payne RS (2007) Lactate, not pyruvate, is neuronal aerobic glycolysis end product: an in vitro electrophysiological study. Neuroscience 147:613-619.

Shimizu H, Watanabe E, Hiyama TY, Nagakura A, Fujikawa A, Okado H, Yanagawa Y, Obata K, Noda M (2007) Glial $\mathrm{Na}_{\mathrm{x}}$ channels control lactate signaling to neurons for brain $\left[\mathrm{Na}^{+}\right]$sensing. Neuron 54:59-72.

Sokoloff L (1960) The metabolism of the central nervous system in vivo. In: Handbook of Physiology, Section I, Neurophysiology, Vol. 3 (Field J, Magoun HW, Hall VE, eds), pp 1843-1864. Washington D.C.: American Physiological Society.

Sokoloff L, Reivich M, Kennedy C, Des Rosiers MH, Patlak CS, Pettigrew KD, Sakurada O, Shinohara M (1977) The $\left[{ }^{14} \mathrm{C}\right]$ deoxyglucose method for the measurement of local cerebral glucose utilization: theory, procedure, and normal values in the conscious and anesthetized albino rat. J Neurochem 28:897-916.

Song Z, Routh VH (2005) Differential effects of glucose and lactate on glucosensing neurons in the ventromedial hypothalamic nucleus. Diabetes 54:15-22.

Suzuki A, Stern SA, Bozdagi O, Huntley GW, Walker RH, Magistretti PJ, Alberini CM (2011) Astrocyte-neuron lactate transport is required for long-term memory formation. Cell 144:810-823.

Territo PR, Mootha VK, French SA, Balaban RS (2000) $\mathrm{Ca}^{2+}$ activation of heart mitochondrial oxidative phosphorylation: role of the $\mathrm{F}_{\mathrm{o}} \mathrm{F}_{1}$-ATPase. Am J Physiol Cell Physiol 278:C423-C435.

Thompson JK, Peterson MR, Freeman RD (2003) Single-neuron activity and tissue oxygenation in the cerebral cortex. Science 299:1070-1072.

van Stroe AJ, Janssen LJJ (1993) Determination of the diffusion coefficient of oxygen in sodium chloride solutions with a transient pulse technique. Analyt Chim Acta 279:213-219.

Wu M, Neilson A, Swift AL, Moran R, Tamagnine J, Parslow D, Armistead S, Lemire K, Orrell J, Teich J, Chomicz S, Ferrick DA (2007) Multiparameter metabolic analysis reveals a close link between attenuated mitochondrial bioenergetic function and enhanced glycolysis dependency in human tumor cells. Am J Physiol 292:C126-C136.

Zhu XH, Zhang Y, Zhang N, Ugurbil K, Chen W (2007) Noninvasive and three-dimensional imaging of $\mathrm{CMRO}_{2}$ in rats at $9.4 \mathrm{~T}$ : reproducibility test and normothermia/ hypothermia comparison study. J Cereb Blood Flow Metab 27:1225-1234. 